\title{
Acute Kidney Injury: Controversies Revisited
}

\author{
Kenneth Yong, ${ }^{1,2}$ Gursharan Dogra, ${ }^{1}$ Neil Boudville, ${ }^{1,2}$ Mary Pinder, ${ }^{3}$ and Wai Lim ${ }^{1}$ \\ ${ }^{1}$ Department of Renal Medicine, Sir Charles Gairdner Hospital, Nedlands, WA 6009, Australia \\ ${ }^{2}$ School of Medicine and Pharmacology, University of Western Australia, Nedlands, WA 6009, Australia \\ ${ }^{3}$ Intensive Care Unit, Sir Charles Gairdner Hospital, Crawley, WA 6009, Australia \\ Correspondence should be addressed to Kenneth Yong, kenneth.yong@health.wa.gov.au
}

Received 1 October 2010; Accepted 7 March 2011

Academic Editor: Achim Jörres

Copyright ( $) 2011$ Kenneth Yong et al. This is an open access article distributed under the Creative Commons Attribution License, which permits unrestricted use, distribution, and reproduction in any medium, provided the original work is properly cited.

This paper addresses the epidemiology of AKI specifically in relation to recent changes in AKI classification and revisits the controversies regarding the timing of initiation of dialysis and the use of peritoneal dialysis as a renal replacement therapy for AKI. In summary, the new RIFLE/AKIN classifications of AKI have facilitated more uniform diagnosis of AKI and clinically significant risk stratification. Regardless, the issue of timing of dialysis initiation still remains unanswered and warrants further examination. Furthermore, peritoneal dialysis as a treatment modality for AKI remains underutilised in spite of potential beneficial effects. Future research should be directed at identifying early reliable biomarkers of AKI, which in conjunction with RIFLE/AKIN classifications of AKI could facilitate well-designed large randomised controlled trials of early versus late initiation of dialysis in AKI. In addition, further studies of peritoneal dialysis in AKI addressing dialysis dose and associated complications are required for this therapy to be accepted more widely by clinicians.

\section{Introduction}

In 2007, the Acute Kidney Injury Network (AKIN) replaced the term acute renal failure with acute kidney injury (AKI) in an attempt to include the entire spectrum of acute renal dysfunction [1]. AKI encompasses a complex clinical entity characterised by an abrupt decline in kidney function which clinically manifests as azotemia, rising serum creatinine, and in most cases oliguria. While recent advances in renal replacement (RRT) and critical therapies have led to improved AKI-related outcomes [2, 3], the incidence of AKI continues to rise, possibly explained by an ageing population with multiple comorbidities and an increase in sepsis-related hospitalisations [2-7]. Furthermore, AKI continues to be associated with significant mortality, hospital length of stay and economic costs, particularly in the context of critically ill patients in the intensive care setting [5, 8-12]. Even relatively modest absolute $(\geq 44 \mu \mathrm{mol} / \mathrm{L})$ and relative $(\geq 25 \%$ from baseline) elevations in creatinine, have been shown to be associated with higher mortality in hospitalised patients $[8,11]$, ranging from $10 \%$ with noncritical AKI managed outside of the intensive care unit (ICU), compared with up to $80 \%$ with critical ICU AKI [13-16].
Although the incidence of AKI continues to rise, the optimum management of AKI remains uncertain with no uniform standard of care, as reflected by wide disparity in clinical practice [17-19]. While multiple studies have addressed the issue of optimal RRT modality and/or RRT dose in critical AKI, the initiation and duration of RRT in critical AKI remains unclear [20-24].

In this paper, we first aim to discuss the epidemiology and mortality outcomes of AKI across a spectrum of severity (critical versus noncritical) as defined by consensus AKI classifications [1, 25]. Secondly, we will review the current literature on dialysis therapies in AKI, more specifically the indications for and optimal timing of initiation of RRT and the role of acute peritoneal dialysis (PD). Finally, we will provide a brief overview on the current state of novel biomarkers of AKI and their potential future role in research and clinical practice.

\section{Definitions of AKI: RIFLE and AKIN}

Definitions for AKI vary widely between studies, ranging from absolute or relative increases in creatinine from baseline 
to the requirement for RRT $[1,25,26]$. The lack of a uniform definition may explain the large differences in reported incidence and outcomes of AKI in the literature, and as a consequence in 2004, a consensus on the definition of acute renal failure known as the Risk-Injury-Failure-Loss-End stage renal disease (RIFLE) classification was reached by a group of international experts [25]. The RIFLE classification was based on two important parameters: (1) changes in serum creatinine or GFR from baseline (2) urine output at specific time points. The severity of acute renal failure was determined by the more severe of the two parameters, which were categorised into three stages. The three stages described in RIFLE include Risk, Injury and Loss, all of which have increasing prognostic significance.

However, with recent studies suggesting that even minor increments in creatinine may be associated with worse outcomes [8], the RIFLE classification was modified by the Acute Kidney Injury Network (AKIN) to include (1) recategorisation of the original RIFLE into AKIN stage 1, 2, and 3, (2) addition of an absolute increase in creatinine $\geq 26 \mu \mathrm{mol} / \mathrm{L}(0.3 \mathrm{mg} / \mathrm{dL}$ ) to stage 1 criteria, and (3) automatic classification of patients starting RRT as stage 3 , regardless of creatinine or urine output [1]. Comparison of the old RIFLE and modified AKIN classification is shown in Table 1.

\section{AKI Epidemiology: Critical versus Noncritical}

Prior to employing the RIFLE/AKIN classifications, the reported incidence of AKI in the literature varied from 1$30 \%$, largely due to lack of a standard definition of AKI $[2,8,10-12,14-16,27-38]$. The incidence of AKI varies according to the location of patients, either in the critical care or noncritical care settings. The noncritical care setting can be further subdivided into community (data from health district, Medicare or district hospital outpatient records), and hospital environments (data from tertiary hospital admissions).

In the critical care setting, the incidence of AKI ranges from $5-20 \%$, typically occurring in patients with severe multiorgan failure [39]. The incidence of AKI as singleorgan failure in the ICU setting is as low as $11 \%$ compared to $69 \%$ in non-ICU settings [13]. There have been two large multi-centre cohort studies examining the incidence of AKI in patients in the critical care setting. The first study was the Beginning and Ending Supportive Therapy for the Kidney (BEST Kidney) which included 29,629 critically ill adult patients admitted to 54 ICUs throughout 23 countries [16]. Using a definition of AKI as oliguria (urine output $<200 \mathrm{~mL} / 12 \mathrm{hrs}$ ) and/or urea $>30 \mathrm{mmol} / \mathrm{L}$ $(84 \mathrm{mg} / \mathrm{dL})$, the authors reported a $5.7 \%$ period prevalence of AKI, (ranging from 1.4\%-25.9\% across all study centres) usually in association with septic $(47.5 \%)$ or cardiogenic (27\%) shock. Approximately two-thirds of patients who developed AKI required RRT ( $4 \%$ of total cohort). The second study was the Program to Improve Care in Acute Renal Disease (PICARD) study. This was a 2-year prospective observational study of 618 ICU patients with AKI across 5 centers in the USA [15]. The authors defined AKI as "newonset" by a rise in creatinine $\geq 44 \mu \mathrm{mol} / \mathrm{L}(\geq 0.5 \mathrm{mg} / \mathrm{dL})$ or "AKI on chronic kidney disease (CKD)" as an increase in creatinine $\geq 88 \mu \mathrm{mol} / \mathrm{L}(\geq 1.0 \mathrm{mg} / \mathrm{dL})$ in patients with baseline creatinine between $133 \mu \mathrm{mol} / \mathrm{L}$ to $433 \mu \mathrm{mol} / \mathrm{L}(1.5 \mathrm{mg} / \mathrm{dL}$ to $4.9 \mathrm{mg} / \mathrm{dL}$ ). RRT was required in $64 \%$ of patients. Similar to the BEST Kidney study, AKI occurred predominantly in patients with multisystem organ failure. The BEST Kidney and PICARD studies are prime examples of the variations in reported incidence and outcomes of AKI when nonstandard definitions of AKI are applied.

With the exception of a few studies in hospitalised children and stem-cell transplant recipients [40, 41], the RIFLE/AKIN classifications are seldom applied in the noncritical care setting (i.e., hospital or community), and variable definitions of AKI continue to confound prevalence and incidence rates. The prevalence of hospital-acquired AKI is thought to be approximately $5-10$ times greater than community-acquired AKI, with reported rates of AKI in 5$7 \%$ of hospitalised patients $[35,42]$. In a study of 4622 patients in a tertiary hospital, Nash et al. reported that $7.2 \%$ of patients developed "renal insufficiency", defined as a $44 \mu \mathrm{mol} / \mathrm{L}$ increase in creatinine in patients with baseline creatinine $\leq 168 \mu \mathrm{mol} / \mathrm{L}$, an $88 \mu \mathrm{mol} / \mathrm{L}$ increase in patients with baseline creatinine $177-433 \mu \mathrm{mol} / \mathrm{L}$, or a $132 \mu \mathrm{mol} / \mathrm{L}$ increase in patients with baseline creatinine $\geq 442 \mu \mathrm{mol} / \mathrm{L}$ [35]. In the Madrid Acute Renal Failure Study Group of 13 tertiary hospitals in Madrid, $u N$ Liaño et al. reported an incidence of AKI of 209 cases per million population $(\mathrm{pmp})$ as defined by a sudden increase in creatinine to level $>177 \mu \mathrm{mol} / \mathrm{L}(2 \mathrm{mg} / \mathrm{dL})$ in patients with normal renal function or an increase of at least 50\% from baseline creatinine in patients with-mild-to moderate chronic renal failure (creatinine $<264 \mu \mathrm{mol} / \mathrm{L}$ ) [34]. Preexisting renal dysfunction was present in about $50 \%$ of patients who developed AKI. RRT was required in $36 \%$ of patients with AKI and was associated with a higher "severity index" of AKI.

Only a handful of studies have examined the incidence of AKI in community settings [43]. The occurrence of AKI in the community is an infrequent event, accounting for $<1 \%$ of hospital admissions in the USA [42, 44]. Early studies from the 1990s have reported overall annual incidence rates of reported community-acquired AKI varying from 22$620 /$ million population, with most studies using need for RRT or cutoff creatinine $\geq 300$ or $500 \mu \mathrm{mol} / \mathrm{L}$ to define AKI $[45,46]$. Using changes in inpatient serum creatinine levels to define AKI, a more recent study by Hsu et al. suggests that the incidence of AKI in the community is increasing over time [4]. The authors reported an increasing incidence of nondialysis AKI and dialysis requiring AKI from 322.7 to 522.4 and 19.5 to 29.5 per 100,000 person years, respectively, between 1996 and 2003 .

Overall observational trends in both the ICU and nonICU settings also suggest the incidence of AKI has risen over time, likely as a reflection of ageing populations with multiple comorbidities (including chronic kidney disease), increased infection-related hospitalisation and increasing utilisation of nephrotoxic agents such as intravenous contrast, aminoglycosides, nonsteroidal anti-inflammatory 
TABLE 1: RIFLE and AKIN classification $[1,25]$.

\begin{tabular}{|c|c|c|c|c|c|}
\hline \multicolumn{3}{|c|}{ RIFLE } & \multicolumn{3}{|c|}{ AKIN } \\
\hline Category & Creatinine/GFR & Urine output (UO) & Stage & Creatinine & Urine output (UO) \\
\hline Risk & $\begin{array}{l}\text { Cr increase by } x 1.5 \text { times or GFR } \\
\text { decrease by } \geq 25 \%\end{array}$ & $\begin{array}{l}\mathrm{UO} \leq 0.5 \mathrm{~mL} / \mathrm{kg} / \mathrm{hr} \text { for } \\
6 \mathrm{hrs}\end{array}$ & Stage 1 & $\begin{array}{l}\text { Cr increase by } x 1.5 \\
\text { times or } \geq 26 \mu \mathrm{mol} / \mathrm{L}\end{array}$ & $\begin{array}{l}\mathrm{UO} \leq 0.5 \mathrm{~mL} / \mathrm{kg} / \mathrm{hr} \\
\text { for } 6 \mathrm{hrs}\end{array}$ \\
\hline Injury & $\begin{array}{l}\text { Cr increase by } x 2 \text { times or GFR } \\
\text { decrease by } \geq 50 \%\end{array}$ & $\begin{array}{l}\mathrm{UO} \leq 0.5 \mathrm{~mL} / \mathrm{kg} / \mathrm{hr} \text { for } \\
12 \mathrm{hrs}\end{array}$ & Stage 2 & Cr increase by $x 2$ & $\begin{array}{l}\mathrm{UO} \leq 0.5 \mathrm{~mL} / \mathrm{kg} / \mathrm{hr} \\
\text { for } 12 \mathrm{hrs}\end{array}$ \\
\hline Failure & $\begin{array}{l}\text { Cr increase by } x 3 \text { times or GFR } \\
\text { decrease by } \geq 75 \% \text { or } \\
\mathrm{Cr} \geq 354 \mu \mathrm{mol} / \mathrm{L} \text { (with acute rise } \geq \\
44 \mu \mathrm{mol} / \mathrm{L} \text { ) }\end{array}$ & $\begin{array}{l}\mathrm{UO} \leq 0.3 \mathrm{~mL} / \mathrm{kg} / \mathrm{hr} \text { for } \\
24 \mathrm{hrs} \text { or anuria for } \\
12 \mathrm{hrs}\end{array}$ & Stage 3 & $\begin{array}{l}\mathrm{Cr} \text { increase by } \mathrm{x} 3 \text { or } \\
\mathrm{Cr} \geq 354 \mu \mathrm{mol} / \mathrm{L} \\
\text { (with acute rise } \\
44 \mu \mathrm{mol} / \mathrm{L} \text { ) or } \mathrm{RRT}^{1}\end{array}$ & $\begin{array}{l}\mathrm{UO} \leq 0.3 \mathrm{~mL} / \mathrm{kg} / \mathrm{hr} \\
\text { for } 24 \mathrm{hrs} \text { or anuria } \\
\text { for } 12 \mathrm{hrs}\end{array}$ \\
\hline Loss (outcome) & $\begin{array}{l}\text { Persistent ARF }=\text { complete loss of } \\
\text { renal function }>4 \text { weeks (but } \leq 3 \\
\text { months) }\end{array}$ & N/A & Nil & & \\
\hline ESRD (outcome) & $\begin{array}{l}\text { Complete loss of renal function }>3 \\
\text { months }\end{array}$ & N/A & Nil & & \\
\hline
\end{tabular}

RRT: renal replacement therapy.

${ }^{1}$ Patients requiring RRT are automatically considered stage 3 AKIN regardless of stage at time of RRT initiation.

drugs (NSAIDs) and chemotherapeutic agents [15, 42, 43]. CKD and sepsis in particular appear to be major contributors to this process. Reports from a US hospital database estimate that patients with CKD stage $3(\mathrm{eGFR}<60 \mathrm{~mL} / \mathrm{min}$ per $1.73 \mathrm{~m}^{2}$ ) have a 2 -fold increase in adjusted odds ratio (OR) of AKI compared to CKD stages 1 and 2 (eGFR $>60 \mathrm{~mL} / \mathrm{min}$ per $1.73 \mathrm{~m}^{2}$ ), with risk progressively increasing with severity of baseline CKD [47]. In a study of sepsis-related admissions in US hospitals, Martin et al. noted an increase in incidence of sepsis-related hospital admissions from 1979 to 2000 which were paralleled by increase in renal failure [7]. Studies have shown that the risk of AKI increases accordingly with severity of sepsis. Schrier et al. reported rates of AKI of 19\% in patients with moderate sepsis, $23 \%$ in patients with severe sepsis and $51 \%$ in patients with positive blood cultures and septic shock [48].

\section{Aetiology of AKI: Critical versus Noncritical}

The cause of AKI differs according to patient location. Acute tubular necrosis (ATN) due to sepsis is generally regarded as the most common cause of AKI in the critical care setting, accounting for up to $35-50 \%$ of all cases of AKI [13, 16, $39,49-51]$. In the BEST Kidney study, septic shock (47.5\%) was the most common aetiology of AKI, followed by major surgery $(34.3 \%)$ and cardiogenic shock $(26.9 \%)$. Similarly, in the PICARD study, ischaemic ATN predominantly attributed to sepsis was listed as the most common aetiology of AKI [15]. The pathogenesis of septic AKI is traditionally thought to involve reduced renal blood flow secondary to systemic arterial vasodilatation and concomitant intrarenal vasoconstriction, resulting in renal hypoperfusion and ischaemia [52]. Interestingly, however, recent experimental animal models of septic AKI have failed to support this longheld hypothesis $[53,54]$. Furthermore, in a recent systematic review of renal histopathology in human and experimental animal septic AKI [55], Langenberg et al. reported that only
$22 \%$ of patients with septic AKI had features of ATN on either renal biopsy or postmortem findings, with the majority of patients having normal or only mild nonspecific histological changes at best. Despite the limitations of this review which include a very small sample size (117 patients), heterogenous definitions of AKI, use of postmortem findings versus renal biopsy, and use of relatively outdated criteria for classic ATN, these findings suggest that ATN is relatively uncommon in the setting of septic AKI. Further studies evaluating the true histolopathology of septic AKI are clearly required.

ATN is also considered the most common cause of AKI in the hospital setting although the aetiology of ATN differs from that of critical care associated AKI. In the Madrid Acute Renal Failure Study, ATN was documented to be the cause of AKI in $75.9 \%$ of ICU patients compared to $37.6 \%$ in non-ICU patients (summarised in Table 2) [13]. ATN within the hospital setting is more likely to be multifactorial, with hypotension and nephrotoxins as important causes in addition to sepsis and surgery [42].

For community-acquired AKI, prerenal or acute-onchronic renal failure are common and usually occurs as the result of dehydration or drug-related toxicities such as nonsteroidal anti-inflammatory drugs (NSAIDs), angiotensinconverting enzyme (ACE) inhibitors and/or angiotensinreceptor blockers (ARB). Elderly and patients with multiple comorbidities such as diabetes are at particularly high risk of developing AKI [44]. In Third World or tropical countries, postinfectious glomerulonephritis, tropical and nontropical infections, snake or spider bites, chemical poisons and traditional herbal medicines are other common causes of community-acquired AKI [42].

\section{RIFLE/AKIN: Classification as a Prognostic Marker in AKI}

Employing the RIFLE/AKIN classifications has facilitated improved risk stratification in critical AKI. In a study of 
1510 ICU patients, increasing mortality rates were reported with greater severity/stages of AKI as defined by RIFLE (mortality rates of $8.8 \%$ with Risk, $11.4 \%$ with Injury, and $26.3 \%$ with Failure) [56]. In a systematic review by Ricci et al. of 24 studies of patients with acute renal failure, application of the RIFLE classification was associated with a stepwise increase in relative risk (RR) for mortality with increasing stages of acute renal failure and across diverse patient populations. In comparison to patients without acute renal failure, the RIFLE Risk category was associated with RR 2.40 (95\% CI 1.94-2.97) of mortality, while Injury and Failure were associated with RR 4.15 (95\% CI 3.14-5.48) and 6.37 (95\% CI 5.14-7.90) of mortality respectively [57]. Although these were retrospective studies and 12 of the 24 studies included only patients with acute renal failure/AKI in the critical care setting, the authors concluded that RIFLE was easily applicable to clinical practice and was a useful tool to help stratify mortality risk in patients with AKI. In a more recent retrospective study by Bagshaw et al. [58] of 120,123 patients from the Australia New Zealand Intensive Care Society Adult Patient Database (ANZICS APD), use of the RIFLE classification identified $36.1 \%$ of patients with AKI out of 120,123 patient admissions to the ICU. AKI was associated with a significant increase in hospital mortality compared to patients without AKI (OR 3.29; 95\% CI 3.19$3.41 ; P<.0001)$. Similarly, each increase in the severity of RIFLE category was also associated with a correspondingly increased risk of hospital mortality.

Studies utilising the AKIN classification in diverse patient populations have also demonstrated comparable findings to studies utilising the RIFLE classification [59-63]. In a large retrospective study of 325,395 critically ill patients from the Veterans Administration ICU system, the development of AKI was associated with mortality risk (OR 2.2, 6.1, and 8.6 for AKIN stage I, II, and III, resp.) [60].

At least, six studies have directly compared the utility of both the RIFLE and AKIN classifications in the prediction of mortality in critical patients with AKI and five of these studies concluded that RIFLE and AKIN were similar in terms of diagnosing AKI and assessing mortality risk [40, 62, 64-68]. In the analysis of the ANZICS APD, Bagshaw et al. found a less than one percent difference in the identification of patients with AKI using either RIFLE/AKIN classifications within the first 24 hours of admission to the ICU [62]. Use of the AKIN classification slightly increased numbers of patients with stage 1 injury (equivalent to "Risk") from $16.2 \%$ to $18.1 \%$, but it decreased the numbers of patients with stage 2 injury (equivalent to RIFLE "Injury") from $13.6 \%$ to $10.1 \%$. The area under ROC for hospital mortality was similar for RIFLE (0.66) and AKIN (0.67) and the authors concluded the AKIN classification did not further improve the sensitivity, robustness or predictive ability of RIFLE in the first $24 \mathrm{hrs}$ of ICU admission.

\section{Mortality in AKI}

$\mathrm{AKI}$ is associated with extremely high mortality rates ranging from $30-80 \%$ in the critical care setting $[12,14-16,27,30$,
TABLe 2: Demographics and AKI outcomes in ICU compared to non-ICU (Madrid Acute Renal Failure Study Group) [13].

\begin{tabular}{|c|c|c|}
\hline & ICU & Non-ICU \\
\hline \multicolumn{3}{|l|}{ Demographics and RRT } \\
\hline Age $(\text { mean } \pm S D)^{a}$ & $56.4 \pm 16.4 \mathrm{yrs}$ & $62.6 \pm 18.8 \mathrm{yrs}$ \\
\hline Males $^{b}$ & $72.7 \%$ & $61.4 \%$ \\
\hline Severity index $(\text { mean } \pm \mathrm{SD})^{a}$ & $0.65 \pm 0.22$ & $0.32 \pm 017$ \\
\hline Single-organ failure $\mathrm{AKI}^{a}$ & $11 \%$ & $69 \%$ \\
\hline $\mathrm{RRT}^{a}$ & $70.8 \%$ & $18.4 \%$ \\
\hline \multicolumn{3}{|l|}{ Cause of AKI } \\
\hline $\mathrm{ATN}^{a}$ & $75.9 \%$ & $37.6 \%$ \\
\hline Prerenal $^{b}$ & $17.8 \%$ & $28.1 \%$ \\
\hline Acute-on-chronic ${ }^{c}$ & $7.9 \%$ & $15.2 \%$ \\
\hline \multicolumn{3}{|l|}{ Mortality } \\
\hline Unadjusted mortality $^{a}$ & $71.5 \%$ & $31.5 \%$ \\
\hline Corrected mortality & $56 \%$ & $15 \%$ \\
\hline $\begin{array}{l}\text { Mortality of single-organ } \\
\text { failure } \mathrm{AKI}^{a}\end{array}$ & $30 \%$ & $23 \%$ \\
\hline
\end{tabular}

37]. In the BEST Kidney and PICARD studies, the overall reported mortality rates were $60 \%$ and $37 \%$, respectively [ 15 , 16].

Studies have consistently observed that patients who develop AKI have a worse mortality than patients without AKI. Bagshaw et al. reported crude hospital mortality rates of $42.7 \%$ and $13.4 \%$ in patients with and without AKI, respectively $(P<.0001)[2]$. Mortality of patients with AKI is substantially increased even further in the setting of concurrent multiorgan failures, sepsis and requirement for RRT. Metnitz et al. demonstrated that patients with AKI requiring RRT had significantly higher in-hospital mortality rates $(62.8 \%)$ compared with patients with AKI not requiring RRT (15.6\%) [12]. Similarly, Bagshaw et al. observed that the presence of sepsis in patients with AKI (compared with nonsepsis related AKI) was associated with greater hospital mortality (70.2\% versus $51.8 \% ; P<.001)$, severity of illness, higher rates of multiorgan failures, a greater requirement for ionotropic and ventilatory support, and a longer duration of hospitalisation [69].

Although it is clear that the presence of AKI in the critical care setting is associated with higher mortality and poor prognosis, uncertainty remains as to whether AKI is directly causal or simply a marker for greater severity of illness and poor patient outcomes.

Evidence for the role of AKI as a "bystander" comes from an observational cohort study of 1396 patients admitted to the ICU showing that patients with AKI had a higher mortality $(23 \%)$ than patients with end-stage renal disease (ESRD) (11\%) and patients without AKI (5\%) [70].

In contrast, other studies suggest that AKI is directly responsible for the high mortality in this group, perhaps through a sustained inflammatory response associated with uraemia. The systemic inflammatory response syndrome 
(SIRS) has been described as a nonspecific generalised inflammatory response to critical illness, initially characterised by systemic release of proinflammatory cytokines followed by a counter anti-inflammatory response syndrome (CARS) aimed at controlling and limiting this inflammatory process. Disruption of these natural responses to inflammation by clinical states such as uraemia, in which proinflammatory and anti-inflammatory cytokines are released simultaneously as opposed to sequentially, has been implicated as a key mechanism in the pathogenesis of multiorgan failure, septic shock, and death [71, 72]. Supporting this hypothesis has been a study demonstrating that patients with critical AKI have simultaneously elevated pro- and antiinflammatory cytokines, which are independent predictors of mortality [73]. Anti-inflammatory cytokines have been shown to induce monocyte hyporesponsiveness to endotoxin and other noxious stimuli, which may in part explain their association with a greater severity of septic shock and possibly poorer patient outcomes [74-76].

As with critical AKI, the presence of AKI in hospitalised non-ICU patients remains an important predictor of mortality [8-11], even after allowing for confounding variations in definitions of AKI. In the study by Nash et al. of AKI in hospitalised patients, mortality associated with renal failure was $19.4 \%$ [35]. Levy et al. reported higher mortality in patients with AKI postradiocontrast procedure (34\%) compared with age- and baseline creatinine matched controls undergoing similar procedures (7\%) [11]. The presence of renal failure defined as an increase in serum creatinine $\geq 25 \%$ from baseline to at least $177 \mu \mathrm{mol} / \mathrm{L}$ $(2 \mathrm{mg} / \mathrm{dL})$ was associated with an adjusted mortality odds ratio (OR) of 5.50 (95\% CI 2.91-13.19; $P<.001)$ but the results were confounded by the fact that no distinction was made between AKI secondary to contrast injury or atheroembolism, which is a common complication of invasive angiography and associated with high mortality.

Finally, in a study of 42,773 patients undergoing cardiac surgery, Chertow et al. reported an overall mortality of $63.7 \%$ in patients who developed AKI (defined crudely as requiring RRT within 30 days of surgery) compared to $4.3 \%$ in patients with no AKI (adjusted OR for death 26; 95\% CI 22-34) [10]. In another report of 9210 patients, Chertow et al. demonstrated that a minor change in serum creatinine ( $\geq 44 \mu \mathrm{mol} / \mathrm{L}$ or $0.5 \mathrm{mg} / \mathrm{dL}$ ) from baseline was associated with a 6.5-fold increased risk of death (95\% CI 5.0-8.5) [8].

\section{Mortality Comparisons between Critical AKI and Noncritical AKI}

While it is widely accepted that mortality associated with critical AKI is higher than noncritical AKI, this may be related to associated multiorgan failure seen in the critical care setting. In a followup study from the Madrid Acute Renal Failure Study Group, Liano et al. prospectively assessed the outcomes of 748 individual AKI episodes comprising of 253 ICU cases and 495 non-ICU patients (results summarised in Table 2) [13]. The authors reported a significantly higher crude mortality in ICU-associated AKI (71.5\%) compared with non-ICU AKI (31.5\%) over a 9 month period $(P<.001)$. However, AKI in the absence of multiorgan failure (i.e., isolated AKI) was rare in the critical care setting compared with the noncritical care setting (11\% ICU versus $69 \%$ non-ICU; $P<.001$ ) but mortality in patients with isolated AKI was comparable between those treated in the critical and noncritical settings (30\% ICU versus 23\% non-ICU; $P=$ NS). Furthermore, analysis of patients with AKI in the presence of multiorgan failure demonstrated a significant linear increase in mortality with increasing number of organ failures, regardless of the location of the patients. The use of RRT was associated with significantly higher mortality in both critical care $(79.3 \%$ versuss $53 \%$; $P<.001)$ and noncritical care settings (40\% versus 30\%; $P<.001)$. It remains debatable as to whether use of RRT was directly responsible for the increased mortality, possibly by enhancing the patient's inflammatory responses.

In a separate retrospective study of 114 patients with dialysis-requiring AKI, Routh et al. reported that there was no association between critical AKI and mortality [77]. Although overall patient survival was significantly lower in critical care compared with noncritical care patients (36\% versus $63 \% ; P<.01$ ), the authors suggested the discrepancy in survival between patient groups was related to the severity of the precipitating illness and concluded that aggressive supportive care was sufficient to eliminate the "morbidity and mortality due to ARF per se". However, a significant limitation of this study was that AKI was defined as having at least one dialysis session in addition to "standard clinical and biochemical criteria" which were not specified. In addition to this, patients in this study were younger compared to patients in more recently published literature, preexisting comorbidities were not recorded and dialysis technologies were significantly different during the study period (1969-1978) compared to the present day. Furthermore, the applicability of this data to current clinical practice is not clear given the trends towards increasingly complex patient disease states and changes in treatment technologies over the last 40 years.

Thus, while mortality is greater in patients with critical AKI compared with noncritical AKI, this may reflect the severity of the underlying illness. Patients with isolated single-organ AKI appear to have a better prognosis compared to patients with AKI in the presence of multiorgan failure and regardless of location, patients with AKI requiring RRT have significantly higher mortality than do patients with AKI that do not require RRT.

\section{Acute Kidney Injury: Current Controversies}

AKI is highly prevalent and is associated with considerable morbidity and mortality, particularly in critically ill patients. Despite this, the optimal use of RRT for AKI remains unclear and has been plagued by controversies which include the optimal timing for initiation of RRT, modality (intermittent haemodialysis (HD) versus continuous renal replacement therapy (CRRT)) and dosing [78]. 
The issue of optimal RRT dose has only recently been better defined by two large multicentre prospective randomised controlled trials; the VA/NIH Acute Renal Failure Trial Network (ATN) study in the USA and the Randomised Evaluation of Normal versus Augmented Level Replacement Therapy (RENAL) study in Australia and New Zealand $[23,79]$. These landmark trials were designed to compare "less intensive" to "intensive" RRT and both failed to demonstrate a survival benefit with higher CRRT doses beyond the current conventional dose of $25 \mathrm{~mL} / \mathrm{kg} / \mathrm{hr}$ in critically ill patients with AKI. Furthermore, with CRRT doses $<20 \mathrm{~mL} / \mathrm{kg} / \mathrm{hr}$, a dose-response relationship towards worse patient outcomes is likely to exist $[78,80]$. This last finding has important implications, given that $46.4 \%$ and $18 \%$ of patients from international surveys such as the BEST Kidney and Do-Re-Mi studies reportedly received a CRRT dose of $<20 \mathrm{~mL} / \mathrm{kg} / \mathrm{hr}[19,81]$. Given that there are often discrepancies between prescribed and delivered CRRT doses as highlighted by the RENAL and ATN trials (delivered dose $10-15 \%$ lower than prescribed), it is advisable that clinicians adjust RRT prescription accordingly $[78,80]$.

The lack of survival benefit with increased RRT dosing places even more importance upon other aspects of RRT, such as the optimal timing for initiation of RRT, as we continue to seek improvements in current AKI outcomes and is discussed below.

\section{Factors Affecting RRT Initiation}

For patients with AKI, the timing and rationale for initiation of RRT varies between critical care and noncritical care settings. In the noncritical care patient with AKI, RRT is regarded as a supportive therapy to be used for prevention of acute uraemic complications. Traditional indications for RRT have been based on criteria used for ESRD patients, such as refractory fluid overload or hyperkalaemia, severe metabolic acidosis, overt uraemia (pericarditis/encephalopathy/neuropathy) or symptomatic progressive azotaemia $[24,95]$.

However, this approach may not be appropriate in assessing the requirement for RRT in patients with critical AKI, particularly in the setting of multiorgan failure [82]. Thus, in contrast, the rationale for initiation of RRT in patients with critical AKI includes factors outside the traditional paradigm described above. Table 3 summarises the relative and absolute recommendations for dialysis $[82,96]$.

Cruz et al. suggest that the presence of specific "critical" conditions should be considered prior to determining whether to initiate RRT in patients with critical AKI. Examples given by the authors include clinical syndromes associated with high catabolic states such as septic shock, burns, or trauma or in other high "metabolic" scenarios such as gastrointestinal bleeding or rhabdomyolysis which often place a greater demand upon renal reserve [97]. Furthermore, based on studies demonstrating an association between positive fluid balance and worse outcomes in critically ill patients with AKI, sepsis, acute lung injury (ALI) and postsurgery, fluid balance management has been identified as another important consideration in the management of patients in the critical care setting [98-104]. It has been hypothesised that fluid overload results in accumulation of fluid in the extracellular compartment due to leaky capillaries. This then leads to visceral oedema, which in turn promotes intra-abdominal hypertension and renal interstitial oedema, both of which may perpetuate AKI [105]. Finally, there is growing data suggesting an important role of the kidneys in the clearance of inflammatory molecules, which may be critical in the pathogenesis of ALI and acute respiratory distress syndrome (ARDS) as well as precipitating and/or exacerbating AKI [106]. While the "criteria" for initiation of RRT based on hypercatabolic states, specific clinical states, fluid status and a pro-inflammatory state remain unclear, these data may be seen to favour earlier initiation of RRT compared with traditional indicators for RRT.

\section{Timing of Initiation of RRT-Haemodialysis}

At present, there is no consensus regarding when to initiate RRT, resulting in a wide variation in clinical practice $[17,18]$.

A major barrier towards determining the optimal timing for RRT initiation has been the lack of agreement over the absolute indications for RRT. A review by Palevsky in 2008 highlighted a few common scenarios of AKI in a critical care setting, whereby the decision for RRT is debatable [24]. It remains unclear whether there is survival benefit in early consideration of RRT in the management of asymptomatic oliguric patients with progressive azotemia or in those with diuretic-resistant renal failure. Furthermore, there are no definitive criteria regarding what levels of hyperkalaemia, acidosis, oliguria or urea/creatinine are acceptable before RRT is initiated for survival benefit. As many of these "criteria" for RRT are based upon physician belief or practice and are derived from studies in ESRD patients, one could question their applicability to AKI patients. Thus, the recommendations published by the Acute Dialysis Quality Initiative (ADQI) for RRT initiation in AKI should be regarded as guidelines only [107]. Moreover, decisions on initiating dialysis in patients with AKI may also be influenced by nonmodifiable or external factors, including age, presence of comorbidities, resource availability, cost and physician preference [24]. A summary of the studies comparing timing of RRT is presented in Table 4 and discussed below.

Despite the presence of several studies attempting to address the optimal timing of RRT in patients with AKI [84-94, 108, 109], their interpretation should take into account the large heterogeneous populations in these studies. Most of the studies are retrospective observational data in which causality between timing of RRT in AKI and outcome cannot be established, and many of the prospective studies have methodological flaws, insufficient sample size and are therefore, underpowered to detect a difference between groups. The lack of a clear-cut definition for AKI, including what constitutes "early" and "late" initiation of RRT further compounds the difficulties in interpreting the data. Finally, an inherent methodological flaw in the literature is that 
TABLE 3: Recommended relative and absolute indications for RRT in critically ill patients with AKI [82].

\begin{tabular}{|c|c|c|}
\hline Dialysis indication & Criteria & Absolute/relative \\
\hline \multirow{7}{*}{ Metabolic } & Urea $>27 \mathrm{mmol} / \mathrm{L}$ & Relative \\
\hline & Urea $>35.7 \mathrm{mmol} / \mathrm{L}$ & Absolute \\
\hline & Hyperkalaemia $>6 \mathrm{mmol} / \mathrm{L}$ & Relative \\
\hline & Hyperkalaemia $>6 \mathrm{mmol} / \mathrm{L}$ plus ECG changes & Absolute \\
\hline & Dysnatraemia & Relative \\
\hline & Hypermagnesaemia $>4 \mathrm{mmol} / \mathrm{L}$ & Relative \\
\hline & $\begin{array}{c}\text { Hypermagnesaemia }>4 \mathrm{mmol} / \mathrm{L} \text { plus anuria or } \\
\text { areflexia }\end{array}$ & Absolute \\
\hline \multirow{2}{*}{ Acidosis } & $\mathrm{pH}>7.15$ & Relative \\
\hline & $\mathrm{pH}<7.15$ & Absolute \\
\hline \multirow{4}{*}{ Anuria/oliguria } & Risk (RIFLE class) & Relative \\
\hline & Injury (RIFLE class) & Relative \\
\hline & Failure (RIFLE class) & Relative \\
\hline & $\mathrm{UO}<200 \mathrm{~mL}$ for $12 \mathrm{hrs}$ or anuria & Absolute \\
\hline \multirow{5}{*}{ Uraemic complication } & Encephalopathy & Absolute \\
\hline & Pericarditis & Absolute \\
\hline & Myopathy & Absolute \\
\hline & Neuropathy & Absolute \\
\hline & Bleeding & Absolute \\
\hline \multirow{2}{*}{ Fluid overload } & Diuretic responsive & Relative \\
\hline & Diuretic resistant (with pulmonary oedema) & Absolute \\
\hline
\end{tabular}

studies have been limited to patients receiving RRT, thus excluding the patient group with AKI who die or recover without RRT. Therefore, any observed benefit of early RRT may be subject to bias by indication, as this may be due to inclusion or exclusion of patients with less severe illness and better prognosis regardless of treatment received.

Earlier studies using various cutoff values of serum urea and creatinine or urine output as criteria for initiation of dialysis regarded commencement of RRT at urea levels $>75 \mathrm{mmol} / \mathrm{L}$ as late initiation of RRT, a level considered unacceptably high by current standards $[83,84]$. In contrast, more recent studies define late initiation as a predialysis urea $>25-28 \mathrm{mmol} / \mathrm{L}$ at time of RRT commencement $[89,94]$.

However, the reliance on urea, creatinine and fluid status/urine output as indicators for initiation of RRT in patients with AKI is controversial. In particular, serum urea, and creatinine are not true markers of kidney injury, require time to accumulate before detection at abnormal levels (48$72 \mathrm{hrs}$ ), and are often influenced by nonrenal factors such as muscle mass, rhabdomyolysis, gastrointestinal haemorrhage and drugs such as corticosteroids [110].

The timing of RRT in patients with AKI was first assessed by Teschan et al. in 1960, who evaluated the effects of "prophylactic" haemodialysis in patients with oliguric AKI [109]. In this case series, the mortality rate of patients with AKI in whom RRT was initiated prior to the urea reaching a level of $71.4 \mathrm{mmol} / \mathrm{L}$ was $33 \%$. This compared favourably with a reported mortality rate of $25-40 \%$ in historical controls. Subsequent reports were based on retrospective case series comparing the effects of early to late RRT initiation over a diverse range of urea cutoff levels $(35-75 \mathrm{mmo} / \mathrm{L})$, all of which suggested improved survival with early RRT [83-85].

Retrospective studies comparing early to late initiation of RRT have generally favoured early RRT. In a retrospective single-center study of 100 trauma patients, patients who developed AKI and received early initiation of RRT (urea $<22.5 \mathrm{mmol} / \mathrm{L}$, mean urea at RRT initiation of $15 \mathrm{mmol} / \mathrm{L}$ ) had improved survival (39\% versus 20\%; $P=.041)$ compared with patients receiving late initiation of RRT (urea $\geq 22.5 \mathrm{mmol} / \mathrm{L}$, mean urea at RRT initiation of $34 \mathrm{mmol} / \mathrm{L}$; $P<.0001$ ) [88]. A greater proportion of patients in the late initiation group had multiorgan failure and sepsis, but there were more oliguric patients in the early group (56\%) than the late group $(39 \% ; P<.01)$. Furthermore, the rationale for starting RRT in the early or late ungroups was unclear. Two retrospective single-centre studies have compared initiation of RRT early (urine output $<100 \mathrm{~mL}$ for $8 \mathrm{hrs}$ ) or late (based on conventional biochemistry parameters) in postcardiac surgery patients with AKI. Both Elahi et al. (22\% versus $43 \% ; P<.05)$ and Demirkiliç et al. (23.5\% versus 55.5\%; $P=.016)$ reported that early initiation of RRT was associated with lower mortality. The mean time to initiation of RRT was significantly different between early and late groups for both studies [90, 91].

Timing of RRT has also been assessed in ICU patients with septic shock and oliguric AKI. In a retrospective singlecentre study, Piccinni et al. compared early initiation of RRT within 12 hrs of ICU admission $(n=40)$ to late initiation of RRT for conventional indications in historical controls $(n=40)$ [92]. Early initiation was associated with 


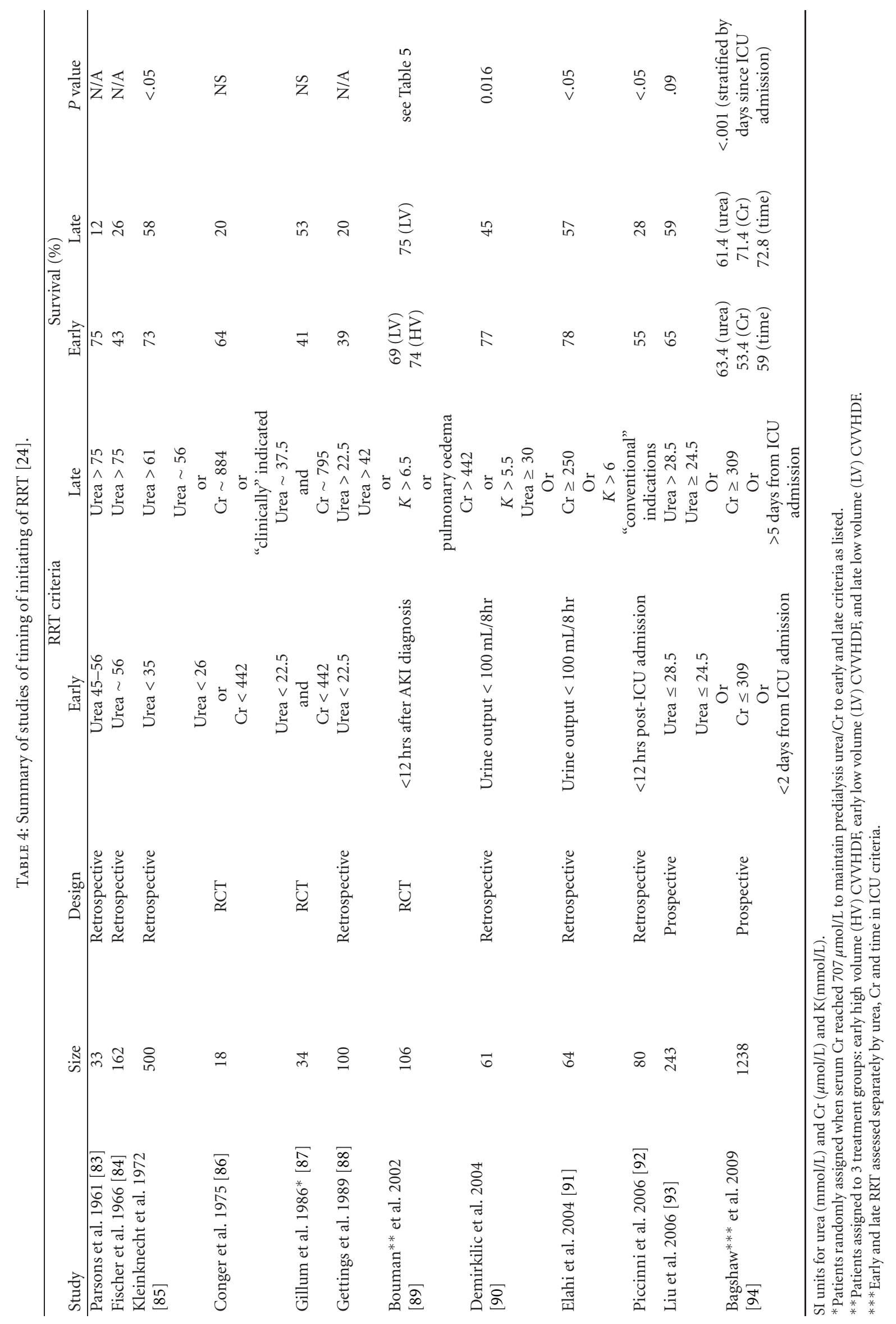


TABLE 5: Time to RRT initiation, predialysis urea and patient cohort survival from Bouman et al. [89].

\begin{tabular}{lccc}
\hline & $\begin{array}{c}\text { Early high volume Group } \\
(n=35)\end{array}$ & $\begin{array}{c}\text { Early low volume Group } \\
(n=35)\end{array}$ & $\begin{array}{c}\text { Late low volume Group } \\
(n=30)\end{array}$ \\
\hline Time between inclusion and first RRT (hrs) & $6.0(3.0-9.7)$ & $7.0(5.0-10.0)$ & $41.8(21.4-72.0)^{a}$ \\
Predialysis urea before first RRT (mmol/L) & $16.3(13.7-20.6)$ & $17.1(14.4-23.5)$ & $37.4(22.0-41.4)^{a}$ \\
Survival $(\%)^{b}$ & 74.3 & 68.8 & 75.0 \\
\hline
\end{tabular}

Data presented as median and interquartile ranges.

${ }^{a} P<.001$ between late low volume group and early groups.

${ }^{b} P=.8$ between groups.

improved 28-day survival (55\% versus $27.5 \%$; $P<.05$ ), gas exchange, haemodynamics and ventilatory wean. However, information on the time between onset of AKI and initiation of RRT was not provided and patients in the late RRT group received a lower dialysis dose.

In a cohort of 98 patients with AKI after major abdominal surgery from the National Taiwan University Surgical ICU Associated Renal Failure (NSARF) Study Group database, Shiao et al. retrospectively applied a simplified RIFLE classification (use of GFR criteria only) to stratify patients receiving early (RIFLE-0/Risk) and late (Injury/Failure) RRT [108]. During the study period, indications for RRT were azotemia with uraemic symptoms (urea $>28 \mathrm{mmol} / \mathrm{L}$ and creatinine $>177 \mu \mathrm{mol} / \mathrm{L}$ ), oligoanuria (urine output $<200 \mathrm{~mL} / 8 \mathrm{hrs}$ ), refractory fluid overload, hyperkalaemia $(K>5.5 \mathrm{mmol} / \mathrm{L})$ and metabolic acidosis ( $\mathrm{pH}<7.20$ ). About $80 \%$ of patients commenced RRT for azotaemia or oligoanuria and $52 \%$ were classified into the early RRT group. Early initiation of RRT was associated with lower in-hospital mortality ( $43.1 \%$ versus $74.5 \%$; $P=.002)$ and predictors of mortality included late RRT (hazard ratio (HR) 1.846; $P=.027$ ), old age, cardiac failure and pre-RRT Sequential Organ Failure Assessment (SOFA) score. A major limitation of this study was that the RIFLE classification used and criteria for initiation of RRT were discrete and separate scoring systems. Therefore the validity of applying RIFLE to stratify into early or late RRT is questionable, especially given that urine output criteria were used in one and not the other.

Initial prospective trials purporting to compare early versus late dialysis can be criticised for having only achieved a comparison between intensive and non-intensive dialysis dose. In a small cohort of 18 patients with post-traumatic AKI during the Vietnam War [86], patients were matched on the basis of similarity of injuries and assigned sequentially and alternately to "intensive" dialysis to maintain a predialysis urea $<26 \mathrm{mmol} / \mathrm{L}$ and creatinine $<442 \mu \mathrm{mol} / \mathrm{L}$, or to "non-intensive" dialysis in which RRT was initiated only when clinically indicated or if the urea and creatinine levels reached $56 \mathrm{mmol} / \mathrm{L}$ or $884 \mu \mathrm{mol} / \mathrm{L}$, respectively. This latter group was assumed to have delayed initiation of dialysis, although details regarding time to initiation of dialysis were not provided. There was a trend toward improved survival in the intensive dialysis compared to non-intensive groups (64\% versus 20\%; $P>.05$ ) in this small study. However, these differences are more attributable to dose of dialysis rather than timing of initiation. Similarly, in a larger prospective controlled trial involving 34 patients with critical AKI, Gillum et al. randomised patients with AKI to intensive haemodialysis targeting a maximum predialysis urea $22.5 \mathrm{mmol} / \mathrm{L}$ and creatinine $442 \mu \mathrm{mol} / \mathrm{L}$, respectively, compared with non-intensive haemodialysis targeting a maximum predialysis urea and creatinine of $<37.5 \mathrm{mmol} / \mathrm{L}$ and $795 \mu \mathrm{mol} / \mathrm{L}$, respectively, [87]. While the mortality rates between intensive and non-intensive groups were similar (58.8\% versus $47.1 \%$; $P<.05)$, the average time from onset of AKI until initiation of dialysis was similar between the intensive and non-intensive groups $(5 \pm 2$ days versus $7 \pm$ 3 days; $P$ value not provideed), and thus, the study failed to examine the effect of timing of initiation of dialysis. The authors concluded that there was no advantage of intensive dialysis in this cohort of patients. As the blood urea and creatinine prior to initiation of dialysis were similar in both groups, no comment can be made regarding the effect of timing of initiation of dialysis.

Bouman et al. randomised 106 critically ill patients requiring ventilator and ionotropic support with AKI into 3 groups: (1) early high-volume CVVHDF $(n=35)$, (2) early low-volume CVVHDF $(n=35)$, and (3) late low-volume CVVHDF $(n=30)$ [89]. AKI was defined as creatinine clearance $<20 \mathrm{~mL} / \mathrm{min}$ and urine output $<180 \mathrm{~mL}$ over $6 \mathrm{hrs}$ despite volume resuscitation. In the early group RRT was commenced within $12 \mathrm{hrs}$ of diagnosis of AKI. In the late group, RRT was initiated when urea $>40 \mathrm{mmol} / \mathrm{L}$ or severe pulmonary oedema occurred. The median times and predialysis urea before first RRT sessions are summarised in Table 5. There were no significant differences in 28-day survival across the 3 groups ( $74.3 \%$ versus $68.8 \%$ versus $75 \%$; $P=.80$ ) and renal function recovered in all survivors at hospital discharge except one patient in the early low-volume group. While this study achieved significant separation in timing of initiation of early versus late dialysis and suggests that timing of initiation and dose of dialysis had no effect on outcome, there were significant limitations to this study. Late RRT was not as late in comparison to other studies. Fifteen patients in the late group (50\%) commenced RRT with urea $<40 \mathrm{mmol} / \mathrm{L}$ due to severe pulmonary oedema and the early group did not receive RRT as early as originally planned due to the requirement for measured creatinine clearance $<20 \mathrm{~mL} / \mathrm{min}$ before inclusion. Furthermore, the overall mortality rate of $27 \%$ was unexpectedly low, reflecting possibly a lower disease burden within the patient cohort.

Data from prospective observational studies on timing of RRT is also conflicting. In a multicentre study based on PICARD, Liu et al. assessed the effects of timing of initiation 
of dialysis in 243 patients with severe AKI and no preexisting CKD [93]. Patients were stratified into early (urea $\leq 28.5 \mathrm{mmol} / \mathrm{L} ; n=122$ ) or late RRT (urea $>28.5 \mathrm{mmol} / \mathrm{L}$; $n=121)$ groups based on urea at initiation of RRT. Late initiation of RRT was associated with an increased relative risk death (RR 1.85; 95\% CI 1.16-2.96) in comparison to the early group, despite a lesser burden of organ failures.

In a large prospective observational multicentre study from the BEST Kidney cohort, Bagshaw et al. compared early versus late initiation of RRT according to urea $(24.2 \mathrm{mmol} / \mathrm{L})$, creatinine $(309 \mu \mathrm{mol} / \mathrm{L})$ and time after ICU admission (early $<2$ days, delayed $2-5$ days, late $>5$ days) in 1238 patients with AKI requiring RRT [94]. Stratification of RRT timing by urea level showed similar mortality for early and late initiation (63.4\% versus $61.4 \%$; OR $0.92 ; 95 \%$ CI $0.73-1.15 ; P=.48$ ), but when stratified by creatinine, late initiation of RRT was associated with lower mortality (71.4\% versus 53.4\%; OR 0.46; 95\% CI 0.36-0.58; $P<.001$ ). When assessed for timing relative to ICU admission, late RRT was associated with higher mortality than delayed or early RRT, respectively, (72.8\% versus $62.3 \%$ versus $59 \%$; $P<$ $.001)$, as well as longer duration of RRT, hospital stay, and greater rates of dialysis dependence. The authors argued the unreliability of AKI biomarkers such as urea and creatinine which vary with clinical states such as fluid overload, GI haemorrhage and muscle mass. They felt that this study supported early initiation of dialysis therapy as defined as time from ICU admission for AKI until such time as more reliable biomarkers of renal injury are available to facilitate early and accurate diagnosis of AKI.

Although not designed to assess the effects of timing of RRT, data from the RENAL and ATN studies have also suggested similar findings with regards to late dialysis as defined by days from time of ICU admission [78]. RRT was commenced much earlier in the RENAL study than the ATN study (median time from ICU admission to first RRT 2.1 days vrsus 6.7 days). However, just over $60 \%$ of patients in the ATN study had received some form of RRT prerandomisation ( $0 \%$ in RENAL) and predialysis urea levels before RRT initiation were similar $(24.2 \mathrm{mmol} / \mathrm{L}$ versus $23.8 \mathrm{mmol} / \mathrm{L}$ ) in the RENAL and ATN studies respectively. Mortality in the RENAL study was lower (45\% mortality at 90 days) than that of the ATN study (53\% mortality at 60 days) and the rate of renal recovery or RRT independence in survivors at 28 days was far superior in the RENAL study $(87 \%$ versus $55 \%)$. Similar differences in favour of the RENAL study are noted when comparisons of renal outcomes at day 60 and 90 between the two studies are made. However, other factors such as differences in patient populations or treatment-related factors between the two trials could account for these findings. For example, 100\% of patients received CRRT in the RENAL trial, while $30 \%$ of patients in the ATN trial were treated with intermittent HD as the first RRT of choice. Therefore, no firm conclusions can be drawn at present.

Finally, a recent meta-analysis of the timing of RRT in patients with AKI has reviewed 23 studies, (5 randomised or quasirandomised trials and 1 prospective and 16 retrospective cohort studies) but did not include the more recent large prospective trial by Seabra et al. [111]. When analysis was confined to randomised trials, early RRT was associated with a $36 \%$ reduction in mortality, but this did not reach statistical significance. In cohort studies, with larger sample size, early RRT was associated with a significant $27 \%$ reduction in mortality risk which did reach statistical significance. Due to the significant heterogeneity between studies (including use of multiple definitions of RRT) and possible publication bias, the authors concluded that while early initiation of RRT in AKI might be associated with better patient survival, the results were inconclusive and larger adequately powered studies were required.

Therefore, the literature on timing of initiation of dialysis has significant limitations and although recent studies suggest that early RRT may be associated with better outcomes, no definitive conclusions can be made. Currently, the decisions on initiation of RRT must be made within the context of each patient, taking into account age, comorbidities, severity of illness and overall clinical state.

\section{Peritoneal Dialysis (PD) and AKI: Current Status}

Compared with HD/CRRT, PD is often overlooked as a form of RRT for AKI in developed countries. In the BEST Kidney study, PD was utilised in only $3.2 \%$ of patients requiring RRT, compared to $80.2 \%$ and $16.9 \%$ for CRRT and intermittent $\mathrm{HD}$, respectively, [16]. However, driven by resource availability, PD is often the only option available for treatment of AKI in developing countries, with potential benefits that include ease of administration, technical simplicity, low bleeding risk, cardiovascular stability, and the absence of an extracorporeal circuit. Furthermore, PD has proven to be a vital resource in situations of natural disaster and massive crush injury whereby basic infrastructure requirements such as adequate power, water supply and manpower are often unavailable [112]. Finally, the use of PD in AKI may be associated with more rapid renal recovery, as suggested by a randomised controlled trial reporting that high volume PD (HVPD) was associated with a significantly shorter time to recovery of renal function $(7.2 \pm 2.6$ days $)$ compared with daily HD (10.6 \pm 4.7 days; $P=.04)$ [113]. The potential for more rapid recovery of renal function is an attractive but relatively unstudied benefit of PD which warrants future investigation. Although only observational data on this aspect of PD and AKI exist, there is biological plausibility given that $\mathrm{PD}$ is associated with superior preservation of residual renal function in ESRD patients $[53,114]$, and is considered a less inflammatory, more physiological form of RRT characterised by greater cardiovascular stability and absence of negative phenomena such as myocardial stunning $[78,79,115,116]$.

The declining use of acute PD in developed countries is predominantly the result of a widely held perception that PD fails to achieve adequate solute clearance, particularly in hypercatabolic patients $[117,118]$. Consequently, the lack of exposure to acute PD has further compounded the situation, resulting in a growing loss of physician familiarity with $\mathrm{PD}$ 
prescription for AKI, techniques, complications and access issues. Other perceived shortcomings of acute PD include the technical expertise required for PD catheter insertion, prerequisite requirement for an intact peritoneal membrane which precludes patients with major abdominal surgery or trauma, risk of peritonitis, protein loss, hyperglycaemia potential for diaphragmatic splinting and inferior fluid balance control [119]. However, limited studies of PD and AKI in selected patients have not reported significant problems with ultrafiltration, hyperglycaemia, or protein loss, and report peritonitis rates that are comparable to catheter infection rates in patients receiving daily HD [113, 120].

\section{Peritoneal Dialysis and AKI-Dose and Small Solute Clearance and Techniques}

Inadequate clearance and RRT dose in critically ill patients with AKI is associated with worse outcomes [121-123]. Unfortunately, the issue of RRT dosing and clearance in acute PD is fraught with controversy. Firstly, there is no consensus on target RRT dose in AKI. Secondly, no studies have examined the effects of different doses of acute PD on outcomes in AKI. Target doses have instead been inferred from studies based on HD/CRRT. Thirdly, whilst RRT dose in AKI is traditionally measured as small-solute (i.e.,urea) clearance, the validity of urea kinetic modelling and the derived $\mathrm{Kt} / V_{\text {urea }}$ formula is questionable given that it was originally designed for use in ESRD patients. Specific criticisms of the application of $K t / V_{\text {urea }}$ to unstable patients with AKI include the inherent unreliability of urea in hypercatabolic states, difficulties in accurately determining volume of urea distribution (often underestimated), and the requirement for a steady state (usually 6 weeks after starting dialysis in ESRD) $[124,125]$. However, despite the limitations outlined above, standardised $K t / V_{\text {urea }}$ remains the most commonly used measure of dose for all dialysis modalities in AKI due to lack of better alternatives.

Based on a prospective study from the Cleveland Clinic Foundation (CCF), the accepted minimum RRT dose for AKI is a single pool $K t / V_{\text {urea }}$ of 1.0 per session, which is equivalent to a standardised $K t / V_{\text {urea }}$ of 2.10 per week (assuming 3-4 sessions of intermittent HD per week) [121]. In this nonrandomised cohort of 844 ICU patients with AKI and requiring first time RRT (intermittent HD), improved survival was observed in patients receiving $K t / V_{\text {urea }}>1.0$ per HD session. Despite conflicting results from subsequent trials by Schiffl et al. [123] and Palevsky et al. [23], a standardised $K t / V_{\text {urea }}$ of 2.10 is now also regarded as an acceptable minimum target dose of PD for AKI [119]. However, it must be remembered that this is a general recommendation only and not a fixed target for all patients, as ultimately the optimal RRT dose for AKI remains unclear.

Selection of an appropriate PD technique is vital for achieving adequate solute clearance and various techniques from chronic PD have been adapted and applied to AKI [126]. Use of flexible PD catheters and techniques such as continuous PD (CPD), tidal PD (TPD) and HVPD have demonstrated the ability to achieve adequate solute clearances.

CPD is similar to continuous ambulatory PD (CAPD) in ESRD patients, in that it involves long 2-6 hr dwells of up to $2 \mathrm{~L}$ dialysate (roughly 4 exchanges/day) [127]. TPD consists of an initial infusion of dialysate (usually $2 \mathrm{~L}$ volume) into the peritoneal cavity. This is followed by partial drainage $(50 \%)$ of the dialysate (tidal drain volume) which is then replaced by fresh dialysate (tidal fill volume). Thus a reserve volume of dialysate perpetually remains in the peritoneal cavity for the duration of the tidal cycle. TPD is aimed at improving dialysis efficacy by minimising time lost during dialysate outflow, increasing dialysate flow rate, and facilitating greater middle molecule clearance by allowing a longer duration of dialysate contact with the peritoneum [128]. In a randomised cross-over study, Chitalia et al. reported a standardisd $K t / V_{\text {urea }}$ of $1.80 \pm 0.32$ and $2.43 \pm$ 0.87 for CPD and TPD, respectively [118].

HVPD is a form of continuous PD therapy designed to achieve high small solute clearance through frequent $2 \mathrm{~L}$ exchanges (18-48 exchanges/day) via a flexible Tenkhoff catheter and automated cycler (total dialysate volume 36$70 \mathrm{~L} /$ day) [129]. In a prospective study of 30 patients with AKI, Gabriel et al. reported a delivered standardised $\mathrm{K} t / V_{\text {urea }}$ of $3.85 \pm 0.62$, using about $36-44 \mathrm{~L}$ dialysate/day. Ultrafiltration volume was also adequate at $2.1 \pm 0.62 \mathrm{~L} /$ day, and serum albumin levels remained stable [129].

\section{Peritoneal Dialysis and AKI-Middle Molecule Clearance}

With recent shifts in philosophy towards middle molecule clearance (500-2000 Da) in AKI [130], PD may be potentially advantageous over $\mathrm{HD}$, as it is generally assumed that middle clearance is superior with PD [131]. However, this may no longer be true with modern-day use of high flux synthetic dialysis membranes [132], and there are no studies available on middle molecule clearance in acute PD. Peritoneal clearance of middle molecules is dependent on both convection and diffusion and is largely determined by the dialysate dwell time [133]. Therefore, increased frequency of exchanges to improve small molecule clearance may impact negatively upon middle molecule clearance in acute PD. Furthermore, the peritoneum is a complex biological entity which actively metabolises and secretes proteins, and this may result in clearance of very different types of middle molecules in comparison to dialysis membranes and filters. Currently, dialysis dose remains determined largely by small solute clearance with no recommendations for middle molecule clearance, and it is suggested that continuous forms of PD therapy which avoid "dry" dwell times such as HVPD be employed for treatment of AKI [119].

\section{Peritoneal Dialysis and AKI-Comparison to HD/CRRT}

There are very few head-to-head comparison of PD and HD in AKI, and the results suggest that with use of correct 
technique, PD is comparable to HD except in one study. Phu et al. randomised patients with AKI requiring dialysis secondary to sepsis/malaria to haemofiltration $(n=34)$ or PD $(n=36)$ [134]. PD was administered via a rigid catheter with use of $2 \mathrm{~L}$ exchanges and 30 minute dwell times (total approximately $70 \mathrm{~L} /$ day) and an average dialysis session length of $26 \mathrm{hrs}$. Dialysis dose and solute clearances were not reported. Compared to haemofiltration, PD was associated with increased mortality (47\% versus $15 \%$; $P=$ .005 ), risk of death (OR 5.1; 95\% 1.6-16), and increased risk of requiring future dialysis (OR 4.70 95\% CI 1.3-17). The authors concluded that haemofiltration was superior to PD for treatment of infection-associated AKI. However, this study had significant limitations including the use of a rigid cathether, $\mathrm{PD}$ exchanges being performed manually with short dwell times, the use of PD solutions which were prepared by the hospital pharmacy and no comparison of dialysis dose or clearance across the different modalities.

Gabriel et al. compared both CPD $(n=60)$ and HVPD $(n=60)$ to daily HD $(n=60)$ in two separate randomised trials $[113,135]$. In the first study comparing CPD and daily $\mathrm{HD}$, standardised $K t / V_{\text {urea }}$ was significantly lower with $\mathrm{CPD}$ compared to $\mathrm{HD}(3.59 \pm 0.61$ versus $4.76 \pm 0.65$; $P<.01)$. There were no differences in metabolic control, survival (58\% versus $52 \% ; P=.48$ ) or dialysis dependence at 30 days $(17 \%$ versus $21 \% ; P=.45)$ between $\mathrm{CPD}$ and HD groups, respectively. However, patients in the CPD group had a shorter duration of therapy (5.5 days versus 7.5 days; $P=.02)$ [135]. Similarly in the second study comparing HVPD and daily HD, standardised $K t / V_{\text {urea }}$ was lower with HVPD in comparison to HD $(3.6 \pm 0.6$ versus $4.7 \pm 0.6$; $P<.01)$. Metabolic control, mortality (58\% versus 53\%; $P=.71)$ and recovery of renal function at 30 days $(83 \%$ versus $77 \% ; P=.45)$ were similar between the HVPD and daily HD groups. Once again, HVPD was associated with a significantly shorter time to recovery of renal function $(7.2 \pm$ 2.6 days versus $10.6 \pm 4.7$ days; $P=.04$ ) [113].

\section{Future Directions: Novel AKI Biomarkers}

Biomarkers were initially discovered with use of screening cDNA microarray technology, which identified several gene subsets undergoing rapid upregulation within hours of initial renal injury $[136,137]$. Our current understanding of biomarkers is that two groups exist: (1) proteins/enzymes which are normal constitutes of renal tubular epithelial cells and are released into the urine as a result of cellular injury (e.g., cystatin C), and (2) inducible proteins which are upregulated in response to cellular injury and are otherwise not normally present (e.g., neutrophil gelatinase-associated lipocalin).

A recent 2008 systematic review has identified several serum and urinary biomarkers including neutrophil gelatinase-associated lipocalin (NGAL), cystatin C (CysC), interleukin-18, kidney injury molecule-1 (KIM-1) and $\mathrm{N}$ acetyl- $\beta$-D-glucosaminidase (NAG), with promising utility for early diagnosis of AKI, diagnosis of established AKI and prediction of outcomes from AKI (requirement for RRT and mortality). However, several issues remain and these biomarkers require further validation in large studies of heterogenous populations, particularly with regards to the applicability of biomarkers to different types of AKI and their additional prognostic value over and above currently used clinical parameters [138]. In addition to this, recent evidence suggests that the predictive ability of biomarkers for AKI is reduced in patients with $\mathrm{CKD}$ (baseline eGFR $<60 \mathrm{~mL} / \mathrm{min}$ per $1.73 \mathrm{~m}^{2}$ ) [139].

As an example, NGAL is highly sensitive for the early diagnosis of AKI in children undergoing cardiac surgery and patients undergoing renal transplantation [140, 141]. Plasma NGAL is also predictive of the requirement for RRT in critically ill adult patients with AKI in the ICU [142]. However, when applied to more heterogenous populations such as the emergency department [143], adults undergoing cardiac surgery [144], and both adults or children in the ICU $[142,145,146]$, the ability of NGAL to detect AKI early is reduced. Furthermore, there is evidence suggesting that NGAL is elevated in the presence of sepsis, multiple preexisting comorbidities and according to the severity of illness, thus confounding its association with AKI [142, 145, 146].

Therefore, further research is required to validate these biomarkers, and ultimately, it would seem that a biomarker panel for AKI which utilises the strengths of each biomarker is required to accurately identify patients with AKI in a timely fashion to allow risk stratification and predict outcomes and the need for RRT. In the research setting and in conjunction with the RIFLE/AKIN classification, biomarkers of AKI may assist in identifying patients at risk of AKI at an earlier stage and may allow clearer delineation of early versus delayed time points for initiation of RRT which can then be applied in a prospective randomised controlled trial.

\section{Summary}

Standardised definitions for AKI, namely, the RIFLE/AKIN classifications, are an essential tool for understanding the epidemiology, aetiology, appropriate management, and prognosis of AKI. Critical and noncritical AKI is highly prevalent with a rising incidence and is associated with high mortality, particularly in the ICU setting. The RIFLE/AKIN classifications have been shown to be good prognostic tools for morbidity and mortality associated with AKI.

The key management controversy in relation to AKI lies around the timing of initiation of RRT. Based on current evidence, the optimal timing for initiation of RRT for patients with AKI remains uncertain and no recommendations can be made beyond the traditional indications currently employed in clinical practice. Well-designed randomised controlled trials of early versus late RRT initiation can be achieved by using the RIFLE consensus definition of AKI to ensure that the early and late treatment arms are uniformly matched with regards to severity of AKI and the use of validated biomarkers of AKI which allows for early identification and randomisation of suitable patients with AKI. Furthermore, treatment decisions should be made upon predetermined criteria (biochemical or others). Finally, in order to reduce 
allocation bias, patients who avoid RRT or die with AKI having not received AKI should be included and analysed on an intention-to-treat basis.

Regarding RRT options for AKI, in patients with an intact peritoneal membrane and AKI, PD seems an acceptable treatment choice with potential benefits. A major barrier towards more widespread use of PD is the lack of consensus on optimal dose of PD and controversial application of data inferred from studies in HD. Further studies of PD in AKI addressing dose, importance of middle molecule clearance and potential PD-related complications such as peritonitisrisk, fluid balance and increased protein loss are required for this therapy to be accepted more widely by clinicians.

Finally, research around emerging AKI biomarkers is promising in identifying markers of early renal injury, which when combined with RIFLE/AKIN classifications may allow timely recognition of AKI to facilitate the much needed trials of early versus late initiation of RRT.

\section{References}

[1] R. L. Mehta, J. A. Kellum, S. V. Shah et al., "Acute kidney injury network: report of an initiative to improve outcomes in acute kidney injury," Critical Care, vol. 11, no. 2, article R31, 2007.

[2] S. M. Bagshaw, C. George, and R. Bellomo, "Changes in the incidence and outcome for early acute kidney injury in a cohort of Australian intensive care units," Critical Care, vol. 11, article R68, 2007.

[3] S. S. Waikar, G. C. Curhan, R. Wald, E. P. McCarthy, and G. M. Chertow, "Declining mortality in patients with acute renal failure, 1988 to 2002," Journal of the American Society of Nephrology, vol. 17, no. 4, pp. 1143-1150, 2006.

[4] C. Y. Hsu, C. E. McCulloch, D. Fan, J. D. Ordoñez, G. M. Chertow, and A. S. Go, "Community-based incidence of acute renal failure," Kidney International, vol. 72, no. 2, pp. 208-212, 2007.

[5] S. S. Waikar, K. D. Liu, and G. M. Chertow, "Diagnosis, epidemiology and outcomes of acute kidney injury," Clinical Journal of the American Society of Nephrology, vol. 3, no. 3, pp. 844-861, 2008.

[6] R. Pisoni, K. M. Wille, and A. J. Tolwani, "The epidemiology of severe acute kidney injury: from BEST to PICARD, in acute kidney injury: new concepts," Nephron Clinical Practice, vol. 109, no. 4, pp. c188-c191, 2008.

[7] G. S. Martin, D. M. Mannino, S. Eaton, and M. Moss, "The epidemiology of sepsis in the United States from 1979 through 2000," The New England Journal of Medicine, vol. 348, no. 16, pp. 1546-1554, 2003.

[8] G. M. Chertow, E. Burdick, M. Honour, J. V. Bonventre, and D. W. Bates, "Acute kidney injury, mortality, length of stay, and costs in hospitalized patients," Journal of the American Society of Nephrology, vol. 16, no. 11, pp. 3365-3370, 2005.

[9] D. W. Bates, L. Su, D. T. Yu et al., "Mortality and costs of acute renal failure associated with amphotericin B therapy," Clinical Infectious Diseases, vol. 32, no. 5, pp. 686-693, 2001.

[10] G. M. Chertow, E. M. Levy, K. E. Hammermeister, F. Grover, and J. Daley, "Independent association between acute renal failure and mortality following cardiac surgery," American Journal of Medicine, vol. 104, no. 4, pp. 343-348, 1998.

[11] E. M. Levy, C. M. Viscoli, and R. I. Horwitz, "The effect of acute renal failure on mortality: a cohort analysis," Journal of the American Medical Association, vol. 275, no. 19, pp. 14891494, 1996.

[12] P. G. H. Metnitz, C. G. Krenn, H. Steltzer et al., "Effect of acute renal failure requiring renal replacement therapy on outcome in critically ill patients," Critical Care Medicine, vol. 30, no. 9, pp. 2051-2058, 2002.

[13] F. Liano, E. Junco, J. Pascual et al., "The spectrum of acute renal failure in the intensive care unit compared with that seen in other settings," Kidney International, vol. 53, no. 66, pp. S16-S24, 1998.

[14] C. Guerin, R. Girard, J.-M. Selli, J.-P. Perdrix, and L. Ayzac, "Initial versus delayed acute renal failure in the intensive care unit: a multicenter prospective epidemiological study," American Journal of Respiratory and Critical Care Medicine, vol. 161, no. 3, part 1, pp. 872-879, 2000.

[15] R. L. Mehta, M. T. Pascual, S. Soroko et al., "Spectrum of acute renal failure in the intensive care unit: the PICARD experience," Kidney International, vol. 66, no. 4, pp. 1613$1621,2004$.

[16] S. Uchino, J. A. Kellum, R. Bellomo et al., "Acute renal failure in critically ill patients: a multinational, multicenter study," Journal of the American Medical Association, vol. 294, no. 7, pp. 813-818, 2005.

[17] P. Overberger, M. Pesacreta, P. M. Palevsky et al., "Management of renal replacement therapy in acute kidney injury: a survey of practitioner prescribing practices," Clinical Journal of the American Society of Nephrology, vol. 2, no. 4, pp. 623630, 2007.

[18] Z. Ricci, C. Ronco, G. D'Amico et al., "Practice patterns in the management of acute renal failure in the critically ill patient: an international survey," Nephrology Dialysis Transplantation, vol. 21, no. 3, pp. 690-696, 2006.

[19] S. Uchino, R. Bellomo, H. Morimatsu et al., "Continuous renal replacement therapy: a worldwide practice survey: the beginning and ending supportive therapy for the kidney (B.E.S.T. Kidney) investigators," Intensive Care Medicine, vol. 33, no. 9, pp. 1563-1570, 2007.

[20] J. A. Kellum, D. C. Angus, J. P. Johnson et al., "Continuous versus intermittent renal replacement therapy: a metaanalysis," Intensive Care Medicine, vol. 28, no. 1, pp. 29-37, 2002.

[21] R. L. Mehta, B. Mcdonald, F. B. Gabbai et al., "A randomized clinical trial of continuous versus intermittent dialysis for acute renal failure," Kidney International, vol. 60, no. 3, pp. 1154-1163, 2001.

[22] C. Ronco, R. Bellomo, P. Homel et al., "Effects of different doses in continuous veno-venous haemofiltration on outcomes of acute renal failure: a prospective randomised trial," The Lancet, vol. 356, no. 9223, pp. 26-30, 2000.

[23] P. M. Palevsky, J. H. Zhang, T. Z. O’Connor et al., "Intensity of renal support in critically ill patients with acute kidney injury," The New England Journal of Medicine, vol. 359, no. 1, pp. 7-20, 2008.

[24] P. M. Palevsky, "Indications and timing of renal replacement therapy in acute kidney injury," Critical Care Medicine, vol. 36, no. 4, pp. S224-S228, 2008.

[25] R. Bellomo, C. Ronco, J. A. Kellum, R. L. Mehta, and P. Palevsky, "Acute renal failure-definition, outcome measures, animal models, fluid therapy and information technology needs: the Second International Consensus Conference of the Acute Dialysis Quality Initiative (ADQI) Group," Critical Care, vol. 8, no. 4, pp. R204-R212, 2004.

[26] J. A. Kellum, C. Ronco, R. Mehta, and R. Bellomo, "Consensus development in acute renal failure: the acute dialysis 
quality initiative," Current Opinion in Critical Care, vol. 11, no. 6, pp. 527-532, 2005.

[27] F. G. Brivet, D. J. Kleinknecht, P. Loirat, and P. J. M. Landais, "Acute renal failure in intensive care units-causes, outcome, and prognostic factors of hospital mortality: a prospective, multicenter study," Critical Care Medicine, vol. 24, no. 2, pp. 192-198, 1996.

[28] G. M. Chertow, C. L. Christiansen, P. D. Cleary, C. Munro, and J. M. Lazarus, "Prognostic stratification in critically ill patients with acute renal failure requiring dialysis," Archives of Internal Medicine, vol. 155, no. 14, pp. 1505-1511, 1995.

[29] G. M. Chertow, J. M. Lazarus, E. P. Paganini, R. L. Allgren, R. A. Lafayette, and M. H. Sayegh, "Predictors of mortality and the provision of dialysis in patients with acute tubular necrosis," Journal of the American Society of Nephrology, vol. 9, no. 4, pp. 692-698, 1998.

[30] L. Cole, R. Bellomo, W. Silvester, and J. H. Reeves, "A prospective, multicenter study of the epidemiology, management, and outcome of severe acute renal failure in a 'closed' ICU system," American Journal of Respiratory and Critical Care Medicine, vol. 162, no. 1, pp. 191-196, 2000.

[31] A. de Mendonça, J. L. Vincent, P. M. Suter et al., "Acute renal failure in the ICU: risk factors and outcome evaluated by the SOFA score," Intensive Care Medicine, vol. 26, no. 7, pp. 915 $921,2000$.

[32] S. H. Hou, D. A. Bushinsky, and J. B. Wish, "Hospitalacquired renal insufficiency: a prospective study," American Journal of Medicine, vol. 74, no. 2, pp. 243-248, 1983.

[33] S. Kresse, H. Schlee, H. J. Deuber, W. Koall, and B. Osten, "Influence of renal replacement therapy on outcome of patients with acute renal failure," Kidney International, vol. 56, no. 72, pp. S75-S78, 1999.

[34] F. Liaño, J. Pascual, C. Gámez et al., "Epidemiology of acute renal failure: a prospective, multicenter, community-based study," Kidney International, vol. 50, no. 3, pp. 811-818, 1996.

[35] K. Nash, A. Hafeez, and S. Hou, "Hospital-acquired renal insufficiency," American Journal of Kidney Diseases, vol. 39, no. 5, pp. 930-936, 2002.

[36] N. Shusterman, B. L. Strom, T. G. Murray, G. Morrison, S. L. West, and G. Maislin, "Risk factors and outcome of hospitalacquired acute renal failure. Clinical epidemiologic study," American Journal of Medicine, vol. 83, no. 1, pp. 65-71, 1987.

[37] W. Silvester, R. Bellomo, and L. Cole, "Epidemiology, management, and outcome of severe acute renal failure of critical illness in Australia," Critical Care Medicine, vol. 29, no. 10, pp. 1910-1915, 2001.

[38] J. H. Turney, D. H. Marshall, A. M. Brownjohn, C. M. Ellis, and F. M. Parsons, "The evolution of acute renal failure, 1956-1988," Quarterly Journal of Medicine, vol. 74, no. 273, pp. 83-104, 1990.

[39] M. Joannidis and P. G. H. Metnitz, "Epidemiology and natural history of acute renal failure in the ICU," Critical Care Clinics, vol. 21, no. 2, pp. 239-249, 2005.

[40] M. Ando, J. Mori, K. Ohashi et al., "A comparative assessment of the RIFLE, AKIN and conventional criteria for acute kidney injury after hematopoietic SCT," Bone Marrow Transplantation, vol. 45, no. 9, pp. 1427-1434, 2010.

[41] M. Zappitelli, B. S. Moffett, A. Hyder, and S. L. Goldstein, "Acute kidney injury in non-critically ill children treated with aminoglycoside antibiotics in a tertiary healthcare centre: a retrospective cohort study," Nephrology Dialysis Transplantation, vol. 26, no. 1, pp. 144-150, 2011.
[42] N. Lameire, W. Van Biesen, and R. Vanholder, "The changing epidemiology of acute renal failure," Nature Clinical Practice Nephrology, vol. 2, no. 7, pp. 364-377, 2006.

[43] J. Himmelfarb and T. A. Ikizler, "Acute kidney injury: changing lexicography, definitions, and epidemiology," Kidney International, vol. 71, no. 10, pp. 971-976, 2007.

[44] J. Kaufman, M. Dhakal, B. Patel, and R. Hamburger, "Community-acquired acute renal failure," American Journal of Kidney Diseases, vol. 17, no. 2, pp. 191-198, 1991.

[45] T. G. Feest, A. Round, and S. Hamad, "Incidence of severe acute renal failure in adults: results of a community based study," British Medical Journal, vol. 306, no. 6876, pp. 481483, 1993.

[46] I. H. Khan, G. R. D. Catto, N. Edward, and A. M. Macleod, "Acute renal failure: factors influencing nephrology referral and outcome," QJM, vol. 90, no. 12, pp. 781-785, 1997.

[47] C. Y. Hsu, J. D. Ordõez, G. M. Chertow, D. Fan, C. E. McCulloch, and A. S. Go, "The risk of acute renal failure in patients with chronic kidney disease," Kidney International, vol. 74, no. 1, pp. 101-107, 2008.

[48] R. W. Schrier and W. Wang, "Acute renal failure and sepsis," The New England Journal of Medicine, vol. 351, no. 2, pp. 159169, 2004.

[49] E. A. J. Hoste, N. H. Lameire, R. C. Vanholder, D. D. Benoit, J. M. A. Decruyenaere, and F. A. Colardyn, "Acute renal failure in patients with sepsis in a surgical ICU: predictive factors, incidence, comorbidity, and outcome," Journal of the American Society of Nephrology, vol. 14, no. 4, pp. 1022-1030, 2003.

[50] J. L. Vincent, D. P. Bota, and D. De Backer, "Epidemiology and outcome in renal failure," International Journal of Artificial Organs, vol. 27, no. 12, pp. 1013-1018, 2004.

[51] J. Klenzak and J. Himmelfarb, "Sepsis and the kidney," Critical Care Clinics, vol. 21, no. 2, pp. 211-222, 2005.

[52] N. Lameire, W. Van Biesen, and R. Vanholder, "Acute renal failure," The Lancet, vol. 365, no. 9457, pp. 417-430, 2005.

[53] M. J. Lysaght, E. F. Vonesh, F. Gotch et al., "Influence of dialysis treatment modality on the decline of remaining renal function," ASAIO Transactions, vol. 37, no. 4, pp. 598-604, 1991.

[54] M. J. Lysaght, J. Moran, C. B. Lysaght, K. Schindhelm, and P. C. Farrell, "Plasma water filtration and lymphatic uptake during peritoneal dialysis," ASAIO Transactions, vol. 37, no. 3, pp. M402-M404, 1991.

[55] C. Langenberg, S. M. Bagshaw, C. N. May, and R. Bellomo, "The histopathology of septic acute kidney injury: a systematic review," Critical Care, vol. 12, no. 1, article R38, 2008.

[56] E. A. J. Hoste, G. Clermont, A. Kersten et al., "RIFLE criteria for acute kidney injury are associated with hospital mortality in critically ill patients: a cohort analysis," Critical Care, vol. 10, no. 3, article R73, 2006.

[57] Z. Ricci, D. Cruz, and C. Ronco, "The RIFLE criteria and mortality in acute kidney injury: a systematic review," Kidney International, vol. 73, no. 5, pp. 538-546, 2008.

[58] S. M. Bagshaw, C. George, I. Dinu, and R. Bellomo, "A multi-centre evaluation of the RIFLE criteria for early acute kidney injury in critically ill patients," Nephrology Dialysis Transplantation, vol. 23, no. 4, pp. 1203-1210, 2008.

[59] F. Barrantes, J. Tian, R. Vazquez, Y. Amoateng-Adjepong, and C. A. Manthous, "Acute kidney injury criteria predict outcomes of critically ill patients," Critical Care Medicine, vol. 36, no. 5, pp. 1397-1403, 2008.

[60] C. V. Thakar, A. Christianson, R. Freyberg, P. Almenoff, and M. L. Render, "Incidence and outcomes of acute kidney 
injury in intensive care units: a Veterans administration study," Critical Care Medicine, vol. 37, no. 9, pp. 2552-2558, 2009.

[61] M. Ostermann and R. Chang, "Correlation between the AKI classification and outcome," Critical Care, vol. 12, no. 6, article R144, 2008.

[62] S. M. Bagshaw, C. George, and R. Bellomo, "A comparison of the RIFLE and AKIN criteria for acute kidney injury in critically ill patients," Nephrology Dialysis Transplantation, vol. 23, no. 5, pp. 1569-1574, 2008.

[63] J. A. Lopes, S. Jorge, S. Gonçalves et al., "Contemporary analysis of the influence of acute kidney injury (AKI) after myeloablative hematopoietic cell transplantation on longterm patient's survival," Bone Marrow Transplantation, vol. 42, no. 2, pp. 139-141, 2008.

[64] M. Zappitelli, C. R. Parikh, A. Akcan-Arikan, K. K. Washburn, B. S. Moffett, and S. L. Goldstein, "Ascertainment and epidemiology of acute kidney injury varies with definition interpretation," Clinical Journal of the American Society of Nephrology, vol. 3, no. 4, pp. 948-954, 2008.

[65] D. N. Cruz, Z. Ricci, and C. Ronco, "Clinical review: RIFLE and AKIN-time for reappraisal," Critical Care, vol. 13, no. 3, p. 211, 2009.

[66] M. Joannidis, B. Metnitz, P. Bauer et al., "Acute kidney injury in critically ill patients classified by AKIN versus RIFLE using the SAPS 3 database," Intensive Care Medicine, vol. 35, no. 10, pp. 1692-1702, 2009.

[67] A. Lassnigg, E. R. Schmid, M. Hiesmayr et al., "Impact of minimal increases in serum creatinine on outcome in patients after cardiothoracic surgery: do we have to revise current definitions of acute renal failure?" Critical Care Medicine, vol. 36, no. 4, pp. 1129-1137, 2008.

[68] J. A. Lopes, P. Fernandes, S. Jorge et al., "Acute kidney injury in intensive care unit patients: a comparison between the RIFLE and the Acute Kidney Injury Network classifications," Critical Care, vol. 12, no. 4, article R110, 2008.

[69] S. M. Bagshaw, S. Uchino, R. Bellomo et al., "Septic acute kidney injury in critically ill patients: clinical characteristics and outcomes," Clinical Journal of the American Society of Nephrology, vol. 2, no. 3, pp. 431-439, 2007.

[70] G. Clermont, C. G. Acker, D. C. Angus, C. A. Sirio, M. R. Pinsky, and J. P. Johnson, "Renal failure in the ICU: comparison of the impact of acute renal failure and end-stage renal disease on ICU outcomes," Kidney International, vol. 62, no. 3, pp. 986-996, 2002.

[71] M. Girndt, U. Sester, H. Kaul, and H. Köhler, "Production of proinflammatory and regulatory monokines in hemodialysis patients shown at a single-cell level," Journal of the American Society of Nephrology, vol. 9, no. 9, pp. 1689-1696, 1998.

[72] M. S. Rangel-Frausto, D. Pittet, M. Costigan, T. Hwang, C. S. Davis, and R. P. Wenzel, "The natural history of the systemic inflammatory response syndrome (SIRS): a prospective study," Journal of the American Medical Association, vol. 273, no. 2, pp. 117-123, 1995.

[73] E. M. Simmons, J. Himmelfarb, M. Tugrul Sezer et al., "Plasma cytokine levels predict mortality in patients with acute renal failure," Kidney International, vol. 65, no. 4, pp. 1357-1365, 2004.

[74] G. Friedman, S. Jankowski, A. Marchant, M. Goldman, R. J. Kahn, and J. L. Vincent, "Blood interleukin 10 levels parallel the severity of septic shock," Journal of Critical Care, vol. 12, no. 4, pp. 183-187, 1997.

[75] A. Marchant, M. L. Alegre, A. Hakim et al., "Clinical and biological significance of interleukin-10 plasma levels in patients with septic shock," Journal of Clinical Immunology, vol. 15 , no. 5, pp. 266-273, 1995.

[76] T. Sfeir, D. C. Saha, M. Astiz, and E. C. Rackow, "Role of interleukin-10 in monocyte hyporesponsiveness associated with septic shock," Critical Care Medicine, vol. 29, no. 1, pp. 129-133, 2001.

[77] G. S. Routh, J. D. Briggs, J. G. Mone, and I. Ledingham McA. I., "Survival from acute renal failure with and without multiple organ dysfunction," Postgraduate Medical Journal, vol. 56, no. 654, pp. 244-247, 1980.

[78] P. Stenvinkel, S. H. Chung, O. Heimbürger, and B. Lindholm, "Malnutrition, inflammation, and atherosclerosis in peritoneal dialysis patients," Peritoneal Dialysis International, vol. 21, no. 3, pp. S157-S162, 2001.

[79] S. Walters, C. Porter, and P. D. Brophy, "Dialysis and pediatric acute kidney injury: choice of renal support modality," Pediatric Nephrology, vol. 24, no. 1, pp. 37-48, 2009.

[80] J. A. Kellum and C. Ronco, "Dialysis: results of RENALwhat is the optimal CRRT target dose?" Nature Reviews Nephrology, vol. 6, no. 4, pp. 191-192, 2010.

[81] S. Vesconi, D. N. Cruz, R. Fumagalli et al., "Delivered dose of renal replacement therapy and mortality in critically ill patients with acute kidney injury," Critical Care, vol. 13, no. 2, article R57, 2009.

[82] N. Gibney, E. Hoste, E. A. Burdmann et al., "Timing of initiation and discontinuation of renal replacement therapy in AKI: unanswered key questions," Clinical Journal of the American Society of Nephrology, vol. 3, no. 3, pp. 876-880, 2008.

[83] F. M. Parsons, S. Hobson, C. R. Blagg, and B. H. Mccracken, "Optimum time for dialysis in acute reversible renal failure. Description and value of an improved dialyser with large surface area," The Lancet, vol. 277, no. 7169, pp. 129-134, 1961.

[84] R. P. Fischer, W. O. Griffen, M. Reiser, and D. S. Clark, "Early dialysis in the treatment of acute renal failure," Surgery Gynecology and Obstetrics, vol. 123, no. 5, pp. 1019-1023, 1966.

[85] D. Kleinknecht, P. Jungers, J. Chanard, C. Barbanel, and D. Ganeval, "Uremic and non-uremic complications in acute renal failure: evaluation of early and frequent dialysis on prognosis," Kidney International, vol. 1, no. 3, pp. 190-196, 1972.

[86] J. D. Conger, "A controlled evaluation of prophylactic dialysis in post traumatic acute renal failure," Journal of Trauma, vol. 15, no. 12, pp. 1056-1063, 1975.

[87] D. M. Gillum, B. S. Dixon, and M. J. Yanover, "The role of intensive dialysis in acute renal failure," Clinical Nephrology, vol. 25, no. 5, pp. 249-255, 1986.

[88] L. G. Gettings, H. N. Reynolds, and T. Scalea, "Outcome in post-traumatic acute renal failure when continuous renal replacement therapy is applied early vs. late," Intensive Care Medicine, vol. 25, no. 8, pp. 805-813, 1999.

[89] C. S. C. Bouman, H. M. Oudemans-van Straaten, J. G. P. Tijssen, D. F. Zandstra, and J. Kesecioglu, "Effects of early high-volume continuous venovenous hemofiltration on survival and recovery of renal function in intensive care patients with acute renal failure: a prospective, randomized trial," Critical Care Medicine, vol. 30, no. 10, pp. 2205-2211, 2002.

[90] U. Demirkiliç, E. Kuralay, M. Yenicesu et al., "Timing of replacement therapy for acute renal failure after cardiac surgery," Journal of Cardiac Surgery, vol. 19, no. 1, pp. 17-20, 2004. 
[91] M. M. Elahi, M. Y. Lim, R. N. Joseph, R. R. V. Dhannapuneni, and T. J. Spyt, "Early hemofiltration improves survival in post-cardiotomy patients with acute renal failure," European Journal of Cardio-thoracic Surgery, vol. 26, no. 5, pp. 1027 1031, 2004.

[92] P. Piccinni, M. Dan, S. Barbacini et al., "Early isovolaemic haemofiltration in oliguric patients with septic shock," Intensive Care Medicine, vol. 32, no. 1, pp. 80-86, 2006.

[93] K. D. Liu, J. Himmelfarb, E. Paganini et al., "Timing of initiation of dialysis in critically ill patients with acute kidney injury," Clinical Journal of the American Society of Nephrology, vol. 1, no. 5, pp. 915-919, 2006.

[94] S. M. Bagshaw, S. Uchino, R. Bellomo et al., "Timing of renal replacement therapy and clinical outcomes in critically ill patients with severe acute kidney injury," Journal of Critical Care, vol. 24, no. 1, pp. 129-140, 2009.

[95] R. Bellomo and C. Ronco, "Indications and criteria for initiating renal replacement therapy in the intensive care unit," Kidney International, vol. 53, no. 66, pp. S106-S109, 1998.

[96] S. M. Bagshaw, D. N. Cruz, R. T. Gibney, and C. Ronco, "A proposed algorithm for initiation of renal replacement therapy in adult critically ill patients," Critical Care, vol. 13, no. 6, p. 317, 2009.

[97] D. N. Cruz, Z. Ricci, S. M. Bagshaw, P. Piccinni, N. Gibney, and C. Ronco, "Renal replacement therapy in adult critically ill patients: when to begin and when to stop," Contributions to Nephrology, vol. 165, pp. 263-273, 2010.

[98] J. Bouchard, S. B. Soroko, G. M. Chertow et al., "Fluid accumulation, survival and recovery of kidney function in critically ill patients with acute kidney injury," Kidney International, vol. 76, no. 4, pp. 422-427, 2009.

[99] D. Payen, A. C. de Pont, Y. Sakr, C. Spies, K. Reinhart, and J. L. Vincent, "A positive fluid balance is associated with a worse outcome in patients with acute renal failure," Critical Care, vol. 12, no. 3, article R74, 2008.

[100] F. Alsous, M. Khamiees, A. DeGirolamo, Y. AmoatengAdjepong, and C. A. Manthous, "Negative fluid balance predicts survival in patients with septic shock: a retrospective pilot study," Chest, vol. 117, no. 6, pp. 1749-1754, 2000.

[101] Y. Sakr, J. L. Vincent, K. Reinhart et al., "High tidal volume and positive fluid balance are associated with worse outcome in acute lung injury," Chest, vol. 128, no. 5, pp. 3098-3108, 2005.

[102] H. P. Wiedemann, A. P. Wheeler, G. R. Bernard et al., "Comparison of two fluid-management strategies in acute lung injury," The New England Journal of Medicine, vol. 354, no. 24, pp. 2564-2575, 2006.

[103] R. M. Stewart, P. K. Park, J. P. Hunt et al., "Less is more: improved outcomes in surgical patients with conservative fluid administration and central venous catheter monitoring," Journal of the American College of Surgeons, vol. 208, no. 5, pp. 725-735, 2009.

[104] B. Brandstrup, H. Tønnesen, R. Beier-Holgersen et al., "Effects of intravenous fluid restriction on postoperative complications: comparison of two perioperative fluid regimens: a randomized assessor-blinded multicenter trial," Annals of Surgery, vol. 238, no. 5, pp. 641-648, 2003.

[105] J. R. Prowle, J. E. Echeverri, E. V. Ligabo, C. Ronco, and R. Bellomo, "Fluid balance and acute kidney injury," Nature Reviews Nephrology, vol. 6, no. 2, pp. 107-115, 2010.

[106] J. L. Koyner and P. T. Murray, "Mechanical ventilation and the kidney," Blood Purification, vol. 29, no. 1, pp. 52-68, 2010.
[107] J. A. Kellum, R. L. Mehta, D. C. Angus, P. Palevsky, and C. Ronco, "The first international consensus conference on continuous renal replacement therapy," Kidney International, vol. 62, no. 5, pp. 1855-1863, 2002.

[108] C. C. Shiao, V. C. Wu, W. Y. Li et al., "Late initiation of renal replacement therapy is associated with worse outcomes in acute kidney injury after major abdominal surgery," Critical Care, vol. 13, no. 5, article R171, 2009.

[109] P. E. Teschan, C. R. Baxter, T. F. O’Brien, J. N. Freuhof, and W. H. Hall, "Prophylactic hemodialysis in the treatment of acute renal failure," Annals of Internal Medicine, vol. 53, pp. 992-1016, 1960.

[110] C. Ronco, S. Grammaticopoulos, M. Rosner et al., "Oliguria, creatinine and other biomarkers of acute kidney injury," Contributions to Nephrology, vol. 164, pp. 118-127, 2010.

[111] V. F. Seabra, E. M. Balk, O. Liangos, M. A. Sosa, M. Cendoroglo, and B. L. Jaber, "Timing of renal replacement therapy initiation in acute renal failure: a meta-analysis," American Journal of Kidney Diseases, vol. 52, no. 2, pp. 272284, 2008.

[112] M. S. Sever, R. Vanholder, and N. Lameire, "Management of crush-related injuries after disasters," The New England Journal of Medicine, vol. 354, no. 10, pp. 1052-1063, 2006.

[113] D. P. Gabriel, J. T. Caramori, L. C. Martim, P. Barretti, and A. L. Balbi, "High volume peritoneal dialysis vs daily hemodialysis: a randomized, controlled trial in patients with acute kidney injury," Kidney International, vol. 73, no. 108, pp. S87-S93, 2008.

[114] L. M. Moist, F. K. Port, S. M. Orzol et al., "Predictors of loss of residual renal function among new dialysis patients," Journal of the American Society of Nephrology, vol. 11, no. 3, pp. 556564, 2000.

[115] M. Haubitz, R. Brunkhorst, E. Wrenger, P. Froese, M. Schulze, and K. M. Koch, "Chronic induction of C-reactive protein by hemodialysis, but not by peritoneal dialysis therapy," Peritoneal Dialysis International, vol. 16, no. 2, pp. 158-162, 1996.

[116] N. M. Selby and C. W. McIntyre, "Peritoneal dialysis is not associated with myocardial stunning," Peritoneal Dialysis International, vol. 31, no. 1, pp. 27-33, 2011.

[117] R. L. Mehta and J. M. Letteri, "Current status of renal replacement therapy for acute renal failure. A survey of US nephrologists. The National Kidney Foundation Council on Dialysis," American Journal of Nephrology, vol. 19, no. 3, pp. 377-382, 1999.

[118] V. C. Chitalia, A. Fernandes Almeida, H. Rai et al., "Is peritoneal dialysis adequate for hypercatabolic acute renal failure in developing countries?" Kidney International, vol. 61, no. 2, pp. 747-757, 2002.

[119] C. Y. Chionh, C. Ronco, F. O. Finkelstein, S. S. Soni, and D. N. Cruz, "Acute peritoneal dialysis: what is the 'adequate' dose for acute kidney injury?" Nephrology Dialysis Transplantation, vol. 25, no. 10, pp. 3155-3160, 2010.

[120] M. J. Blumenkrant, G. M. Gahl, and J. D. Kopple, "Protein losses during peritoneal dialysis," Kidney International, vol. 19, no. 4, pp. 593-602, 1981.

[121] E. P. Paganini, M. Tapolyai, M. Goormastic et al., "Establishing a dialysis therapy/patient outcome link in intensive care unit acute dialysis for patients with acute renal failure," American Journal of Kidney Diseases, vol. 28, no. 5, supplement 3, pp. S81-S89, 1996.

[122] Z. Ricci and C. Ronco, "Dose and efficiency of renal replacement therapy: continuous renal replacement therapy versus intermittent hemodialysis versus slow extended daily 
dialysis," Critical Care Medicine, vol. 36, supplement 4, pp. S229-S237, 2008.

[123] H. Schiffl, S. M. Lang, and R. Fischer, "Daily hemodialysis and the outcome of acute renal failure," The New England Journal of Medicine, vol. 346, no. 5, pp. 305-310, 2002.

[124] H. Schiffl, "Utility of urea kinetic modelling for prescription of adequate intermittent dialysis in critically ill maintenance dialysis patients," Nephrology Dialysis Transplantation, vol. 22, no. 7, p. 2096, 2007.

[125] J. Himmelfarb, J. Evanson, R. M. Hakim, S. Freedman, Y. Shyr, and T. A. Ikizler, "Urea volume of distribution exceeds total body water in patients with acute renal failure," Kidney International, vol. 61, no. 1, pp. 317-323, 2002.

[126] C. Y. Chionh, S. Soni, D. N. Cruz, and C. Ronco, "Peritoneal dialysis for acute kidney injury: techniques and dose," Contributions to Nephrology, vol. 163, pp. 278-284, 2009.

[127] R. W. Steiner, "Continuous equilibration peritoneal dialysis in acute renal failure," Peritoneal Dialysis International, vol. 9, no. 1, pp. 5-7, 1989.

[128] A. Agrawal and K. D. Nolph, "Advantages of tidal peritoneal dialysis," Peritoneal Dialysis International, vol. 20, no. 2, pp. S98-S100, 2000.

[129] D. P. Gabriel, G. V. Ribeiro do Nascimento, J. T. Caramori, L. C. Martim, P. Barretti, and A. L. Balbi, "High volume peritoneal dialysis for acute renal failure," Peritoneal Dialysis International, vol. 27, no. 3, pp. 277-282, 2007.

[130] C. Ronco, J. A. Kellum, R. Bellomo, and A. A. House, "Potential interventions in sepsis-related acute kidney injury," Clinical Journal of the American Society of Nephrology, vol. 3, no. 2, pp. 531-544, 2008.

[131] D. Sethi, C. M. B. Murphy, E. A. Brown, B. R. Muller, and P. E. Gower, "Clearance of beta-2-microglobulin using continuous ambulatory peritoneal dialysis," Nephron, vol. 52, no. 4, pp. 352-355, 1989.

[132] P. Evenepoel, B. Bammens, K. Verbeke, and Y. Vanrenterghem, "Superior dialytic clearance of $\beta$-microglobulin and p-cresol by high-flux hemodialysis as compared to peritoneal dialysis," Kidney International, vol. 70, no. 4, pp. 794-799, 2006.

[133] D. F. Brophy, K. M. Sowinski, M. A. Kraus, S. M. Moe, J. E. Klaunig, and B. A. Mueller, "Small and middle molecular weight solute clearance in nocturnal intermittent peritoneal dialysis," Peritoneal Dialysis International, vol. 19, no. 6, pp. 534-539, 1999.

[134] N. H. Phu, T. T. Hien, N. T. H. Mai et al., "Hemofiltration and peritoneal dialysis in infection-associated acute renal failure in Vietnam," The New England Journal of Medicine, vol. 347, no. 12, pp. 895-902, 2002.

[135] D. P. Gabriel, J. T. Caramori, L. C. Martin, P. Barretti, and A. L. Balbi, "Continuous peritoneal dialysis compared with daily hemodialysis in patients with acute kidney injury," Peritoneal Dialysis International, vol. 29, supplement 2, pp. S62-S71, 2009.

[136] P. Devarajan, J. Mishra, S. Supavekin, L. T. Patterson, and S. S. Potter, "Gene expression in early ischemic renal injury: clues towards pathogenesis, biomarker discovery, and novel therapeutics," Molecular Genetics and Metabolism, vol. 80, no. 4, pp. 365-376, 2003.

[137] M. T. Nguyen, G. F. Ross, C. L. Dent, and P. Devarajan, "Early prediction of acute renal injury using urinary proteomics," American Journal of Nephrology, vol. 25, no. 4, pp. 318-326, 2005.

[138] S. G. Coca, R. Yalavarthy, J. Concato, and C. R. Parikh, "Biomarkers for the diagnosis and risk stratification of acute kidney injury: a systematic review," Kidney International, vol. 73, no. 9, pp. 1008-1016, 2008.

[139] J. L. Koyner, V. S. Vaidya, M. R. Bennett et al., "Urinary biomarkers in the clinical prognosis and early detection of acute kidney injury," Clinical Journal of the American Society of Nephrology, vol. 5, no. 12, pp. 2154-2165, 2010.

[140] J. Mishra, C. Dent, R. Tarabishi et al., "Neutrophil gelatinaseassociated lipocalin (NGAL) as a biomarker for acute renal injury after cardiac surgery," The Lancet, vol. 365, no. 9466, pp. 1231-1238, 2005.

[141] C. R. Parikh, A. Jani, J. Mishra et al., "Urine NGAL and IL-18 are predictive biomarkers for delayed graft function following kidney transplantation," American Journal of Transplantation, vol. 6, no. 7, pp. 1639-1645, 2006.

[142] D. N. Cruz, M. De Cal, F. Garzotto et al., "Plasma neutrophil gelatinase-associated lipocalin is an early biomarker for acute kidney injury in an adult ICU population," Intensive Care Medicine, vol. 36, no. 3, pp. 444-451, 2010.

[143] T. L. Nickolas, M. J. O’Rourke, J. Yang et al., “Sensitivity and specificity of a single emergency department measurement of urinary neutrophil gelatinase-associated lipocalin for diagnosing acute kidney injury," Annals of Internal Medicine, vol. 148, no. 11, pp. 810-819, 2008.

[144] G. Wagener, M. Jan, M. Kim et al., "Association between increases in urinary neutrophil gelatinase-associated lipocalin and acute renal dysfunction after adult cardiac surgery," Anesthesiology, vol. 105, no. 3, pp. 485-491, 2006.

[145] M. Zappitelli, K. K. Washburn, A. A. Arikan et al., "Urine neutrophil gelatinase-associated lipocalin is an early marker of acute kidney injury in critically ill children: a prospective cohort study," Critical Care, vol. 11, article R84, 2007.

[146] S. M. Bagshaw, M. Bennett, M. Haase et al., "Plasma and urine neutrophil gelatinase-associated lipocalin in septic versus non-septic acute kidney injury in critical illness," Intensive Care Medicine, vol. 36, no. 3, pp. 452-461, 2010. 


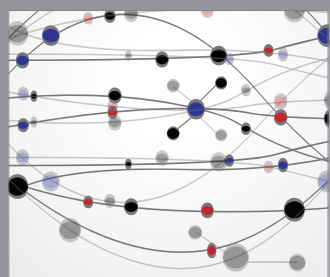

The Scientific World Journal
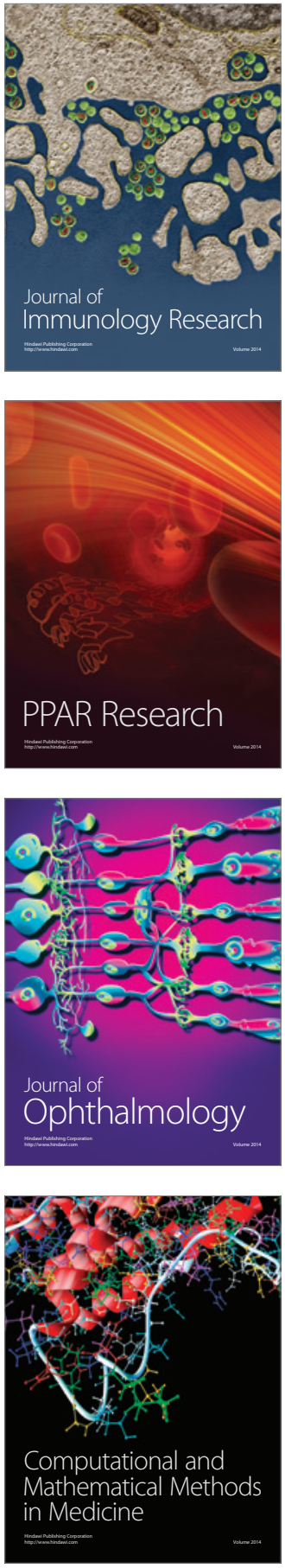

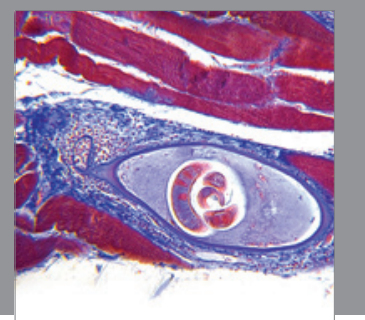

Gastroenterology

Research and Practice
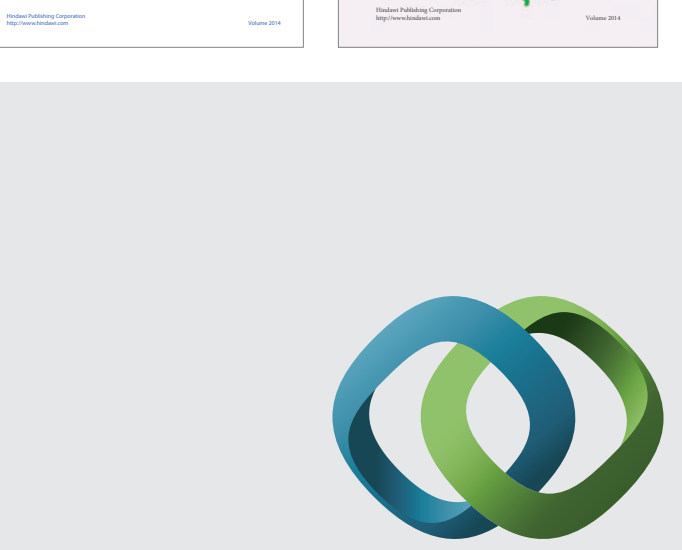

\section{Hindawi}

Submit your manuscripts at

http://www.hindawi.com
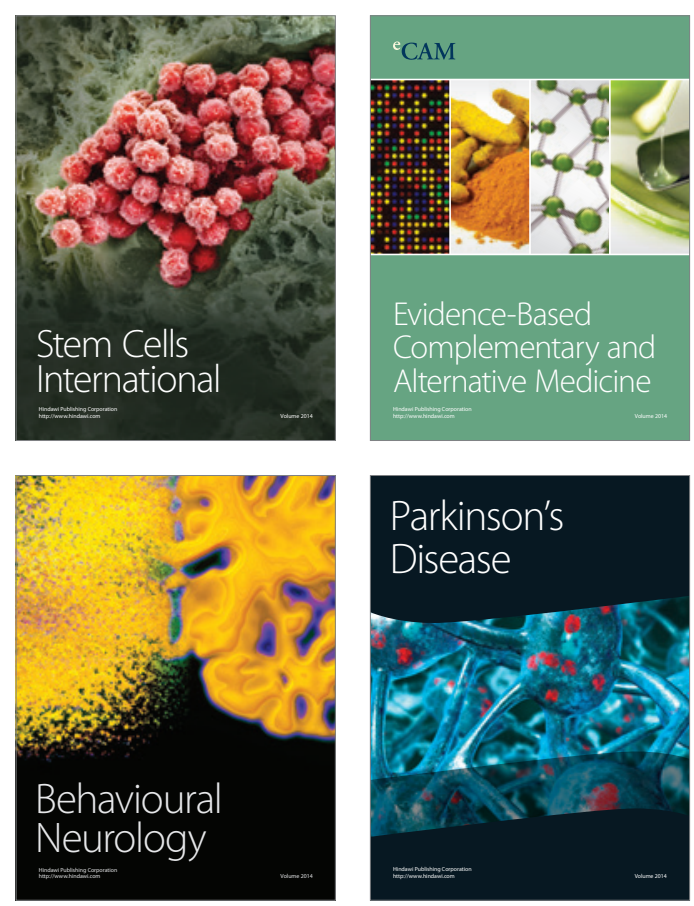

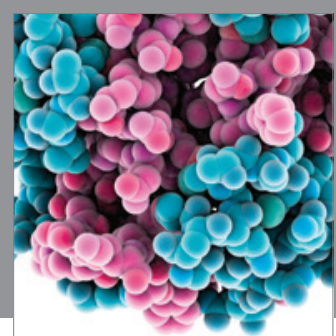

Journal of
Diabetes Research

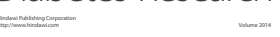

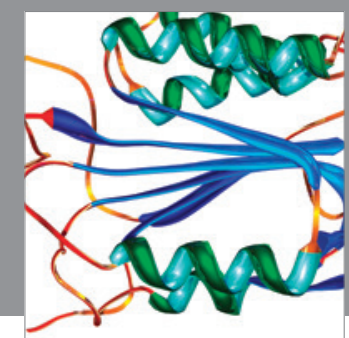

Disease Markers
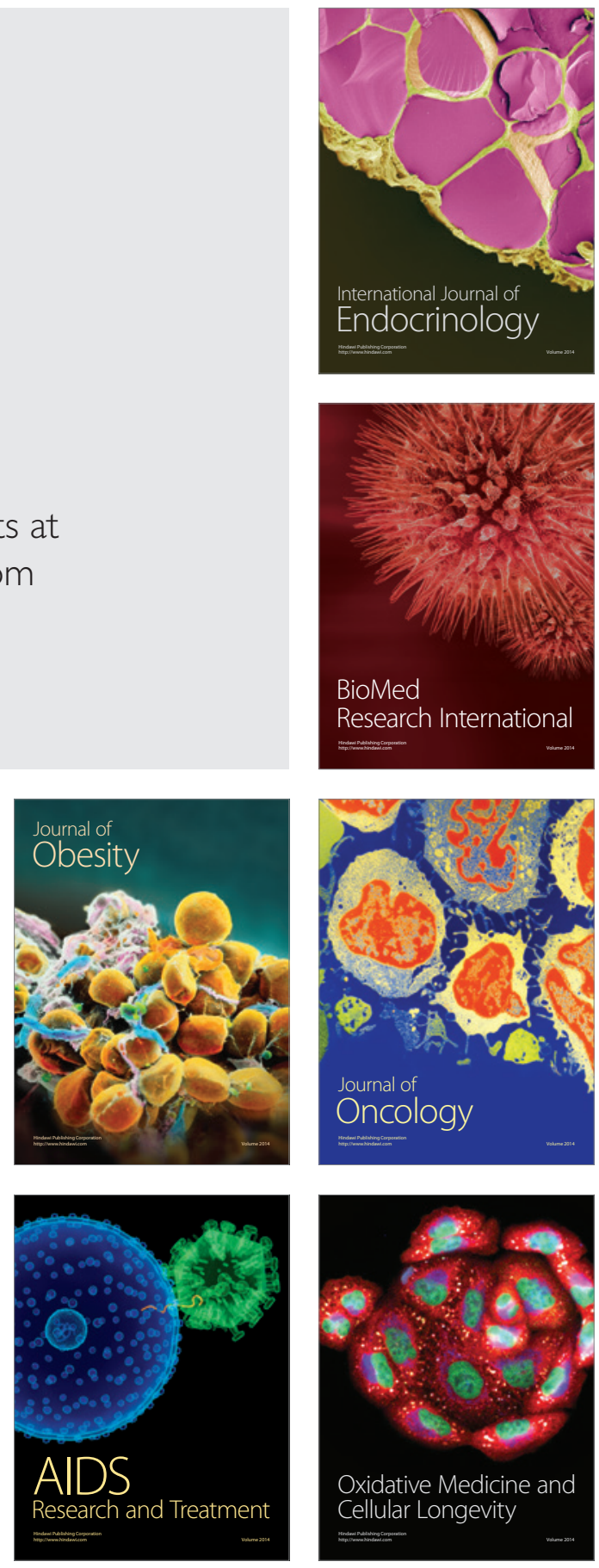